\title{
Targeting the adenosine $2 \mathrm{~A}$ receptor enhances chimeric antigen receptor $\mathrm{T}$ cell efficacy
}

\author{
Paul A. Beavis,, Melissa A. Henderson, ${ }^{1,2}$ Lauren Giuffrida, ${ }^{1,2}$ Jane K. Mills, ${ }^{1,2}$ Kevin Sek, ${ }^{1,2}$ Ryan S. Cross, ${ }^{1,2}$ \\ Alexander J. Davenport, ${ }^{1,2}$ Liza B. John,, ${ }^{1,2}$ Sherly Mardiana,, ${ }^{1,2}$ Clare Y. Slaney, ${ }^{1,2}$ Ricky W. Johnstone, ${ }^{1,2}$ Joseph A. Trapani,, \\ John Stagg, ${ }^{3,4}$ Sherene Loi, ${ }^{1,2}$ Lev Kats, ${ }^{1,2}$ David Gyorki, ${ }^{5}$ Michael H. Kershaw, ${ }^{1,2,6,7}$ and Phillip K. Darcy ${ }^{1,2,6,7}$

\begin{abstract}
'Cancer Immunology Program, Peter MacCallum Cancer Centre, East Melbourne, Victoria, Australia. ${ }^{2}$ Sir Peter MacCallum Department of Oncology, University of Melbourne, Parkville, Victoria, Australia. ${ }^{3}$ Centre de Recherche du Centre Hospitalier de l'Université de Montréal, Institut du Cancer de Montréal, Montréal, Quebec, Canada. ${ }^{4}$ Faculté de Pharmacie, Université de Montréal, Pavillon Jean-Coutu, Montréal, Quebec, Canada. ${ }^{5}$ Division of Cancer Surgery, Peter MacCallum Cancer Centre. ${ }^{6}$ Department of Immunology, Monash University, Clayton, Victoria, Australia. ${ }^{7}$ Department of Pathology, University of Melbourne, Parkville, Victoria, Australia.
\end{abstract}

\begin{abstract}
Chimeric antigen receptor (CAR) T cells have been highly successful in treating hematological malignancies, including acute and chronic lymphoblastic leukemia. However, treatment of solid tumors using CAR T cells has been largely unsuccessful to date, partly because of tumor-induced immunosuppressive mechanisms, including adenosine production. Previous studies have shown that adenosine generated by tumor cells potently inhibits endogenous antitumor $T$ cell responses through activation of adenosine $2 A$ receptors $\left(A_{2 A} R s\right)$. Herein, we have observed that CAR activation resulted in increased $A_{2 A} R$ expression and suppression of both murine and human CAR T cells. This was reversible using either $A_{2 A} R$ antagonists or genetic targeting of $A_{2 A} R$ using shRNA. In 2 syngeneic HER2+ self-antigen tumor models, we found that either genetic or pharmacological targeting of the $A_{2 A} R$ profoundly increased CAR T cell efficacy, particularly when combined with PD-1 blockade. Mechanistically, this was associated with increased cytokine production of CD8+ CAR T cells and increased activation of both $\mathrm{CD8}^{+}$and $C D 4^{+}$CAR T cells. Given the known clinical relevance of the CD73/adenosine pathway in several solid tumor types, and the initiation of phase I trials for $A_{2 A} R$ antagonists in oncology, this approach has high translational potential to enhance CAR T cell efficacy in several cancer types.
\end{abstract}

\section{Introduction}

The success of immunotherapy in cancer in recent years has highlighted the potential to utilize a patient's immune system to eradicate cancer. With adoptive cellular therapy, this conventionally involves ex vivo expansion of a patient's tumor-infiltrating lymphocytes (TILs) to reinfuse a population of T lymphocytes that contains clones responsive to tumor antigens. While this approach has been successful in melanoma (1), and to a lesser extent in other cancers such as renal cell carcinoma (2) and glioma (3), it is not broadly applicable to multiple cancer types because of the low frequency of TILs within the microenvironment of less immunogenic tumors. To circumvent this problem, a patient's peripheral blood $\mathrm{T}$ lymphocytes can be genetically modified to express a transgenic T cell receptor (TCR) (4) or a chimeric antigen receptor (CAR) (5) to target a known tumor antigen. This approach enables the generation of large numbers of tumor-specific T cells. CARs are composed of a Fab fragment that recognizes a tumor antigen linked to an intracellular domain with the signaling domains of CD3 and CD28 and/or 4-1BB. The incorporation of CD28/4-1BB signaling domains leads to more robust $\mathrm{T}$ cell activation and consequently

Authorship note: M.H. Kershaw and P.K. Darcy contributed equally to this work. Conflict of interest: The authors have declared that no conflict of interest exists. Submitted: July 11, 2016; Accepted: December 12, 2016. Reference information: J Clin Invest. 2017;127(3):929-941. https://doi.org/10.1172/JCl89455. more potent antitumor effects (6-9). CAR T cells have been highly successful in hematological malignancies such as acute lymphoblastic leukemia (10) and chronic lymphoblastic leukemia $(11,12)$, but their success in solid cancers has been limited to date (13). The reasons for this are not fully understood but include the need to traffic to a solid tumor site (as opposed to hematological disease) and immunosuppression in the local tumor microenvironment. A number of preclinical studies have shown that CAR T cell efficacy can be improved in the solid tumor setting by targeting of tumor immunosuppressive mechanisms $(14,15)$. Notably, we have previously shown that blockade of PD-1 with a monoclonal antibody can enhance the antitumor activity of CAR T cells (16). Similarly, reversal of PD-1 signaling through a chimeric PD-1/CD28 construct has been shown to enhance CAR T cell function (17). One immunosuppressive pathway that has recently gained attention as a potential target to reverse tumor-induced immunosuppression is the production of adenosine. Adenosine is found at immunosuppressive concentrations within the tumor microenvironment (18) and can be generated from extracellular ATP in a stepwise manner by the ectoenzymes CD39 and CD73 (19). CD73 is expressed on both tumor cells and host immunosuppressive cells such as Tregs and myeloid-derived suppressor cells (MDSCs). CD73 expression has been shown to negatively correlate with patient prognosis in a number of cancer types (20-22), highlighting the relevance of the CD73/adenosine immunosuppressive axis in patients. Furthermore, preclinical studies have shown that targeting of either CD73 
A

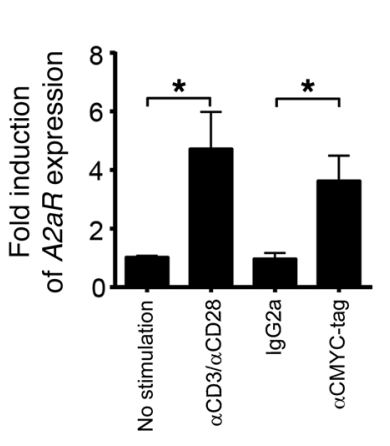

B

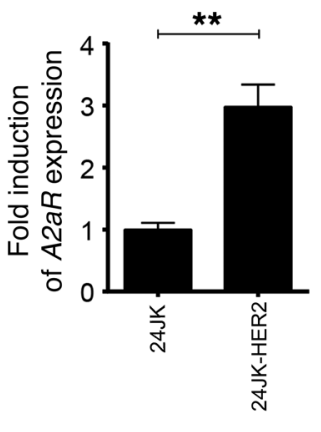

C

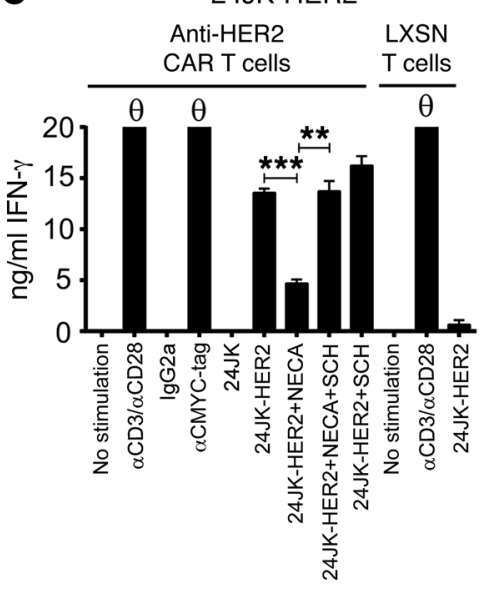

D

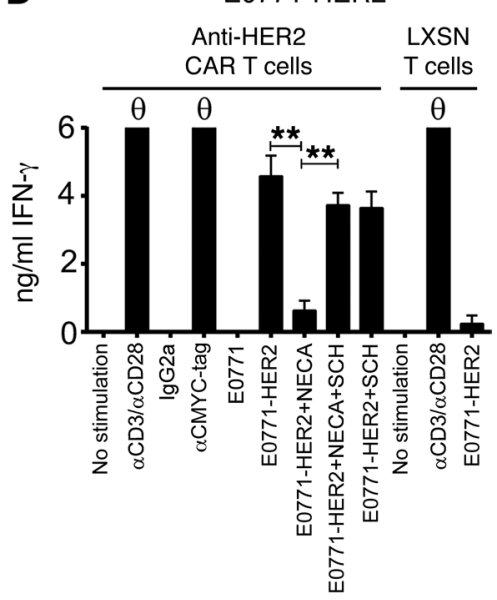

E

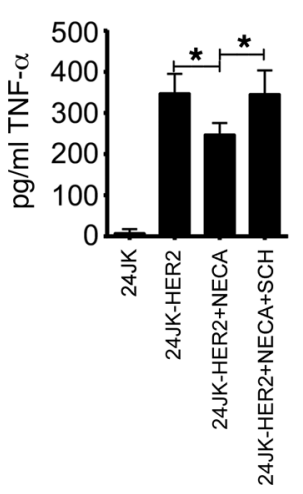

24JK-HER2

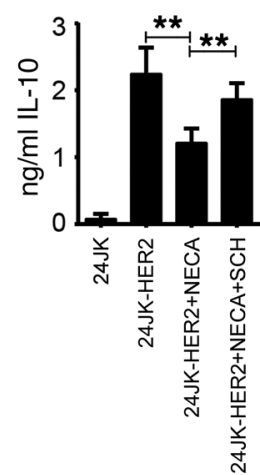

$\mathbf{F}$

E0771-HER2

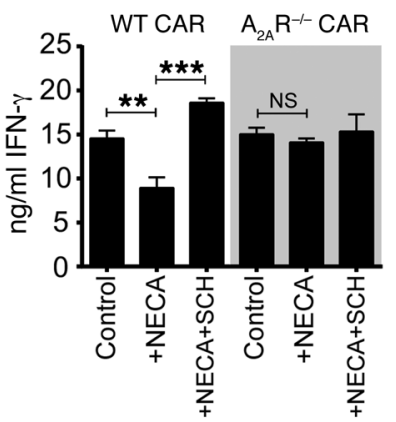

E0771-HER2

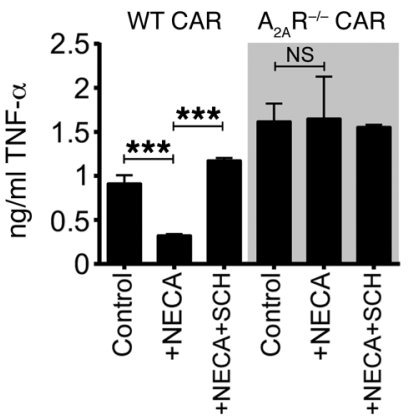

Figure 1. Stimulation of the CAR results in upregulation of the $\mathbf{A}_{2 \mathrm{~A}} \mathbf{R}$, which limits CAR T cell cytokine production. (A) $2 \times 10^{6}$ murine anti-HER2 CAR T cells were stimulated overnight with either anti-CD3 $(0.5 \mu \mathrm{g} / \mathrm{ml}) /$ anti-CD28 $(0.5 \mu \mathrm{g} / \mathrm{ml})$, anti-CMYC tag $(1: 1,000)$, or an isotype control. (B) $1 \times 10^{6}$ CAR T cells were cocultured with $1 \times 10^{6} 24 \mathrm{JK}$ or $24 \mathrm{JK}$-HER2 tumor cells for 4 hours. (A and B) Stimulated cells were lysed and RNA isolated. Expression of $A 2 a R$ and housekeeping gene $L 32$ was determined by GPCR. (A) Data were normalized to unstimulated CAR T cells and are presented as the mean \pm SEM of 4 individual experiments. (B) Data are presented as the mean \pm SD from a representative experiment of $n=3$. (C-F) $2 \times 10^{5}$ CAR T cells were cocultured with $1 \times 10^{5}$ 24JK/24JK-HER2 (C and E) or E0771/E0771-HER2 (D and F) tumor cells in the presence or absence of NECA $(1 \mu \mathrm{M})$ and SCH58261 ( $\left.1 \mu \mathrm{M}\right)$. Supernatants were collected after 16 hours and the cytokine concentration determined. Data are represented as mean \pm SD of triplicates from a representative experiment of $n=4$. " $\theta$ " indicates that the recorded value was above the maximum indicated on the graph. "LXSN T cells" refers to T cells transduced with the empty retroviral vector (LXSN) control. ${ }^{*} P<0.05,{ }^{* *} P<0.01,{ }^{* * *} P<0.001$ by 1 -way ANOVA; NS, not significant.

or CD39 with either monoclonal antibodies or pharmacological inhibitors can enhance antitumor immunity (23-26). An alternative strategy is to target the downstream adenosine receptors. Adenosine binds to 4 known receptors: $A_{1}, A_{2 A}$ (herein referred to as $\left.A_{2 A} R\right), A_{2 B}$, and $A_{3}$. Although $A_{2 B}$ and $A_{3}$ are also expressed on $\mathrm{T}$ cells, adenosine is thought to predominantly suppress endogenous antitumor $\mathrm{T}$ cell responses through stimulation of $\mathrm{A}_{2 \mathrm{~A}} \mathrm{Rs}$ expressed on activated $\mathrm{T}$ cells $(18,23,24,27-31)$. Indeed, $\mathrm{A}_{2 \mathrm{~A}} \mathrm{R}$ deficient mice (hereafter referred to as $\mathrm{A}_{2 \mathrm{~A}} \mathrm{R}^{-/-}$mice) are resistant to the immunosuppressive effects of adenosine and elicit enhanced antitumor immune responses $(18,27,32,33)$.

Targeting the $\mathrm{A}_{2 \mathrm{~A}} \mathrm{R}$ is a highly translational approach to blocking this axis, since $A_{2 A} R$ antagonists have already undergone clinical trials for Parkinson's disease (34). The potential of targeting this receptor is underlined by the emergence of clinical trials using $\mathrm{A}_{2 \mathrm{~A}} \mathrm{R}$ antagonists in oncology (ClinicalTrials.gov, NCTO2655822). In the current study we investigated whether targeting adenosinemediated immunosuppression could enhance CAR T cell activity.
We have previously reported that $A_{2 A} R$ blockade synergizes with anti-PD-1 by enhancing endogenous antitumor immune responses $(33,35)$, and so we hypothesized that this combination may also enhance CAR T cell activity.

Herein, we demonstrate, for the first time to our knowledge, that CAR T cells upregulate $A_{2 A}$ Rs upon antigen-specific stimulation in vitro and in vivo. Consequently, $\mathrm{A}_{2 \mathrm{~A}} \mathrm{R}$-deficient CAR T cells had significantly greater therapeutic efficacy than WT CAR T cells. Moreover, we observed that blockade of $\mathrm{A}_{2 \mathrm{~A}}$ Rs using 2 distinct pharmacological compounds enhanced the efficacy of CAR T cell responses, particularly in the setting of PD-1 blockade. The effect coincided with increased activation of both $\mathrm{CD} 8^{+}$and $\mathrm{CD} 4^{+} \mathrm{CAR} \mathrm{T}$ cells and was dependent on increased IFN- $\gamma$ production by CAR T cells. Moreover, we show that primary melanomas express both HER2 and $\mathrm{CD} 73$ and that $\mathrm{A}_{2 \mathrm{~A}} \mathrm{R}$ activation limits the efficacy of patient-derived anti-HER2 CAR T cells. Our data strongly suggest that $A_{2 A} R$ targeting could be used in combination with CAR T cells and checkpoint blockade to significantly increase the clinical utility of CAR T cells. 
A
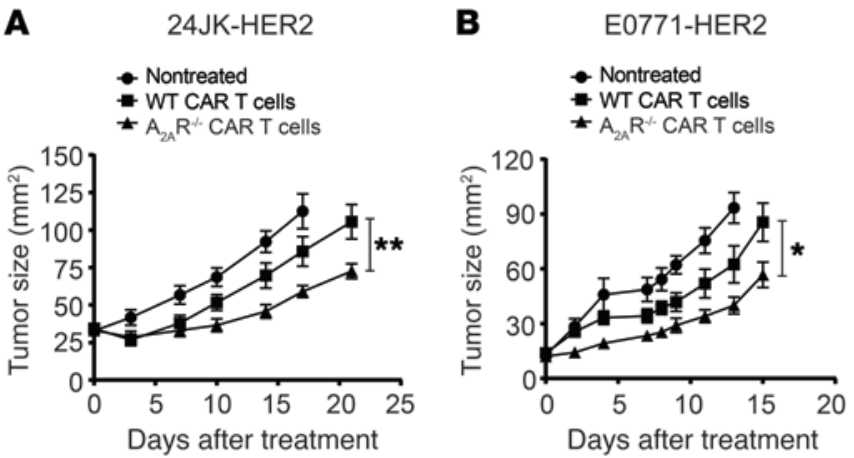

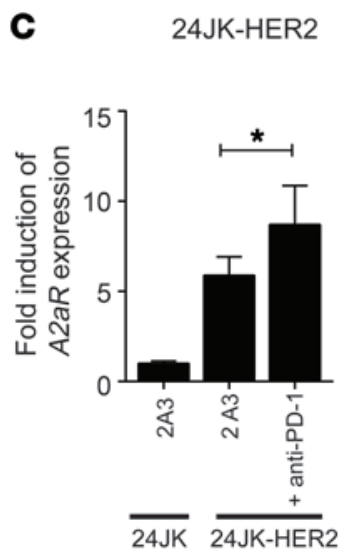

D
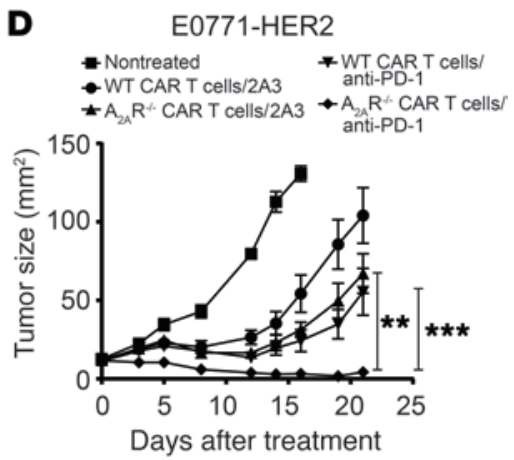

Days after treatment

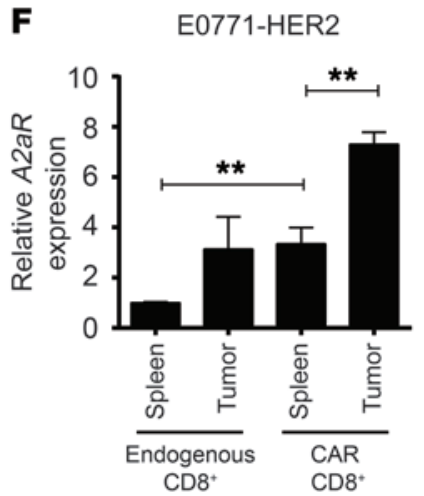

Figure 2. $A_{2 A} R$ is upregulated on CAR T cells in vivo and limits their antitumor efficacy. C57BL/6-HER2 mice were injected with $1 \times 10^{6} 24 J \mathrm{~K}-\mathrm{HER} 2$ (subcutaneous) (A) or $1 \times 10^{5}$ E0771-HER2 tumor cells (B and D-F). (A, B, D, and E) Mice were injected with $1 \times 10^{7}$ CAR T cells derived from WT or $A_{2 A} R^{-1-}$ splenocytes on days 7 and 8 after tumor injection following total-body irradiation (5 Gy) on day 7. Mice were injected with 50,000 IU IL-2 on days 0-4 after T cell transfer and, where indicated, with anti-PD-1 (200 $\mu \mathrm{g} /$ mouse) or $2 \mathrm{~A} 3$ isotype control on days 0,4 , and 8 after T cell transfer. (C) $1 \times 10^{6} 24 \mathrm{JK}-$ HER2 tumor cells were cocultured with $1 \times 10^{6}$ anti-HER2 CAR T cells for 48 hours in the presence of anti-PD-1 (50 $\mu \mathrm{g} / \mathrm{ml}$ ) or $2 \mathrm{A3}$ isotype control. A further $1 \times 10^{6} 24 \mathrm{JK}$-HER2 tumor cells were added after 24 hours to provide chronic stimulation. Cells were lysed after 48 hours. Expression of $A_{2 A} R$ is shown relative to T cells cocultured with 24JK parental tumor cells. (F) E0771-HER2 tumor-bearing mice were treated as above with Ly5.1+ CAR T cells. Nine days after T cell transfer, tumors and spleens of tumor-bearing mice were pooled, and CAR (Ly5.1 $1^{+}$) and endogenous (CD45.2+) CD8 $8^{+}$cells were FACS sorted. Expression of $A 2 a R$ on these subsets was determined by GPCR in triplicate. (A, B, and D) Data are presented as the mean \pm SEM of 6-8 mice from a representative experiment of $n=3$. (C) Data are represented as the mean \pm SD from a representative experiment of $n=2$. (E) Survival endpoint was when tumor size reached $>100 \mathrm{~mm}^{2}$. Data are shown for pooled experiments with $n=14-24$ per group. ${ }^{*} P<0.05,{ }^{* *} P<0.01,{ }^{* * *} P<0.001$ by 2 -way ANOVA

(A, B, and D), 1-way ANOVA (C and F), or Mantel-Cox test (E).

\section{Results}

Activation of the CAR leads to increased expression of the $A_{2 A} R$. Although $\mathrm{A}_{2 \mathrm{~A}} \mathrm{R}$ is known to be upregulated following TCR activation and consequently suppresses $\mathrm{T}$ cell responses, the effect of CAR stimulation on the expression of $A_{2 A} R s$ is not known. Moreover, the ability of adenosine to suppress CAR T cell responses has not been investigated. To examine this we first transduced primary murine splenocytes with a CAR containing the CD28 and CD3 $\zeta$ signaling domains recognizing the human HER2 antigen ( $\mathrm{scFv}-\mathrm{CD} 28-\zeta)$. Murine splenocytes were activated and retrovirally transduced with an anti-HER2 CAR. Consistent with our previous results (16), after 7 days of culture in IL-2/IL-7-containing media, the anti-HER2 $\mathrm{T}$ cells were predominantly $\mathrm{CD}^{+} \mathrm{T}$ cells $(78 \% \pm 4 \%)$ with only a smaller percentage of $\mathrm{CD} 4^{+} \mathrm{T}$ cells present in the culture $(15 \%$ $\pm 4 \%$ ) (Supplemental Figure 1; supplemental material available online with this article; https://doi.org/10.1172/JCI89455DS1). To determine whether activation of the CAR induced upregulation of the $A_{2 A} R, T$ cells were activated with either an anti-myc tag anti- body that directly stimulates the CAR via a c-myc epitope incorporated within the scFv, or anti-CD3/CD28 monoclonal antibodies as a positive control. These experiments revealed that stimulation of gene-modified $\mathrm{T}$ cells through the CAR results in upregulation of the $A_{2 A} R$ at levels equivalent to those achieved following TCR stimulation (Figure 1A). To investigate whether this effect was also observed following recognition of HER2 expressed on tumor target cells, anti-HER2 CAR T cells were cocultured with either 24JK mouse fibrosarcoma cells, or 24JK cells engineered to express human HER2 as previously described (ref. 36 and Supplemental Figure 2A). Coculture with 24JK-HER2 tumor cells significantly increased $\mathrm{A}_{2 \mathrm{~A}} \mathrm{R}$ expression on anti-HER2 CAR T cells, confirming that CAR activation resulted in upregulation of the $A_{2 A} R$ (Figure $1 B)$. These data provided a strong rationale to investigate further the effect of $\mathrm{A}_{2 \mathrm{~A}} \mathrm{R}$ stimulation on CAR T cell activity.

$A_{2 A} R$ blockade enhances the in vitro activity of CAR $T$ cells. To investigate the functional consequence of $\mathrm{A}_{2 \mathrm{~A}} \mathrm{R}$ expression, we determined the cytokine production of CAR $\mathrm{T}$ cells following 


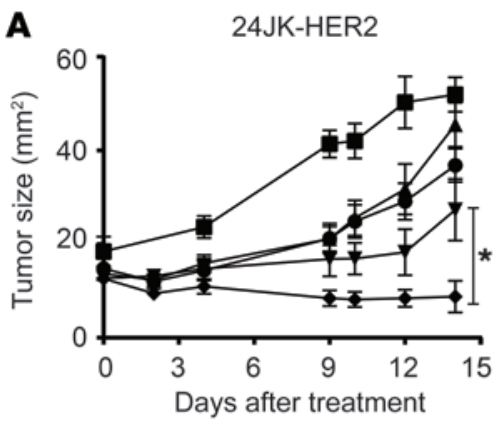

C

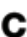

B
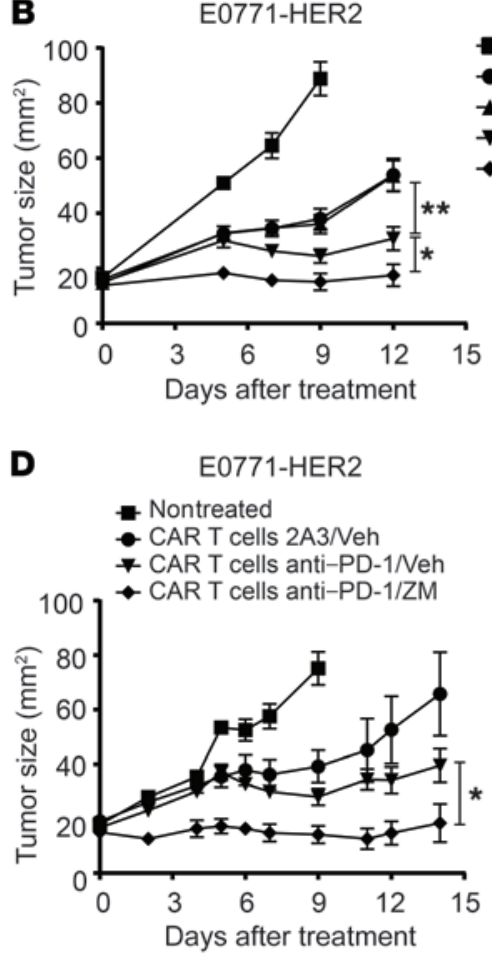
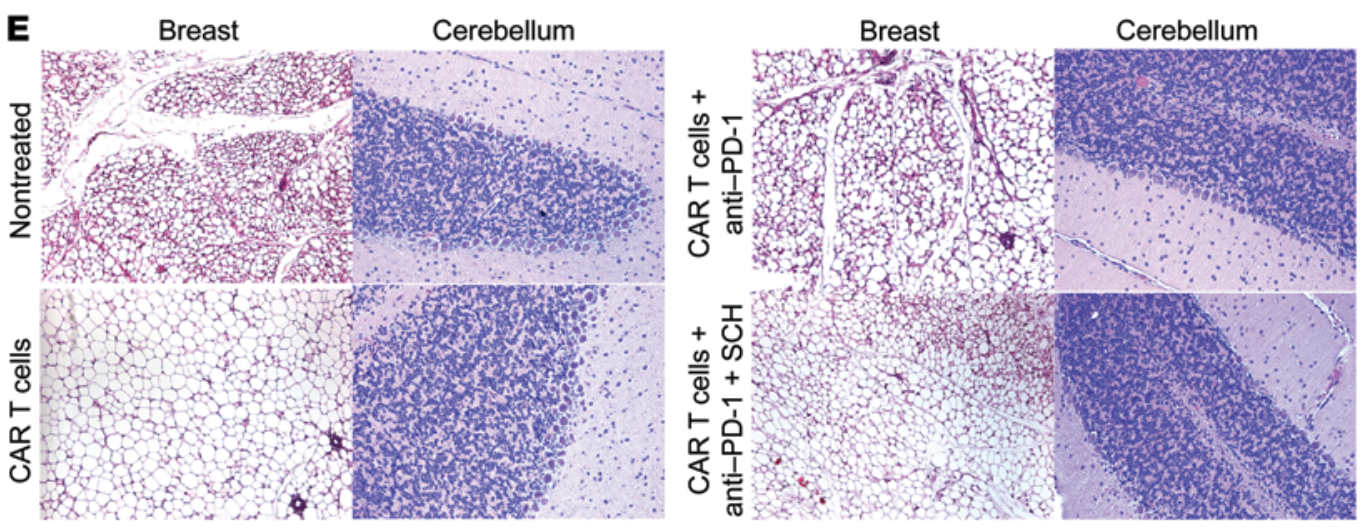

Figure 3. $A_{2 A} R$ blockade enhances the efficacy of CAR T cells in combination with anti-PD-1 without inducing autoimmune pathology. C57BL/6-HER2 mice were injected with $1 \times 10^{6}$ 24JK-HER2 (subcutaneous) (A) or $1 \times 10^{5}$ E0771-HER2 tumor cells (B-E) and treated with WT CAR T cells and anti-PD-1 or 2A3 per Figure 2. Mice were also treated daily with either $1 \mathrm{mg} / \mathrm{kg}$ SCH58261 (A-C), $1 \mathrm{mg} / \mathrm{kg}$ ZM241385 (D), or vehicle control (A, B, and D). Data are presented as the mean \pm SEM of 6-14 mice. (C) Data are shown for $n=18-28$ per group with tumors greater than $100 \mathrm{~mm}^{2}$ taken as the cutoff for survival. (E) H\&E sections were taken from the cerebellum and breast (non-tumor-inoculated) in E0771-HER2 tumor-bearing mice undergoing therapy at day 9 after T cell injection. Representative sections are shown at an original magnification of $\times 200$. ${ }^{*} P<0.05,{ }^{* *} P<0.01$ by 2 -way ANOVA (A, B, and D) or Mantel-Cox test (C).

coculture with 24JK-HER2 or E0771-HER2 (a murine breast cancer line engineered to express human HER2; Supplemental Figure 2A) tumor cells in the presence or absence of the adenosine analog $5^{\prime}$-( $N$-ethylcarboxamido)adenosine (NECA). NECA is an agonist of all known adenosine receptors $\left(\mathrm{A}_{1}, \mathrm{~A}_{2 \mathrm{~A}}, \mathrm{~A}_{2 \mathrm{~B}}\right.$, and $\left.\mathrm{A}_{3}\right)$ and was used at $1 \mu \mathrm{M}$, a dose that mimics the concentration of adenosine found in the tumor microenvironment. In these experiments we observed high levels of IFN- $\gamma$ produced by anti-HER2 CAR T cells following antigen-specific stimulation with either 24JK-HER2 (Figure 1C) or E0771-HER2 (Figure 1D) tumor cells. The addition of NECA significantly and potently suppressed cytokine production by CAR T cells cocultured with E0771-HER2 or 24JK-HER2 cells, an effect that was almost fully reversed by the addition of the $A_{2 A} R$ antagonist SCH58261 (Figure 1, C and D). Intracellular cytokine staining of anti-HER2 CAR T cells following coculture with 24JK-HER2 tumor cells revealed that NECA significantly suppressed IFN- $\gamma$ production of both $\mathrm{CD} 8^{+}$and $\mathrm{CD} 4^{+} \mathrm{CAR}$ T cells (Supplemental Figure 3A). To more broadly investigate the effect of $A_{2 \mathrm{~A}} \mathrm{R}$ activation on CAR $\mathrm{T}$ cell function, we investigated the effect of $\mathrm{A}_{2 \mathrm{~A}} \mathrm{R}$ stimulation on the production of TNF- $\alpha$, IL-10, IL-2, and IL-4. These experiments revealed that $\mathrm{A}_{2 \mathrm{~A}} \mathrm{R}$ activation similarly suppressed anti-HER2 CAR $\mathrm{T}$ cell production of TNF- $\alpha$ and IL-10 (Figure 1E), while IL-2 and IL-4 were not secreted at detectable levels following coculture with HER2-expressing tumor cells (Supplemental Figure 3B). 
Interestingly, $\mathrm{A}_{2 \mathrm{~A}} \mathrm{R}$ activation had minimal impact on the cytotoxicity of CAR T cells, reflected in the killing of HER2 ${ }^{+}$target cells in chromium release assays (Supplemental Figure 4A) or staining for the degranulation marker CD107a (Supplemental Figure $4, \mathrm{~B}$ and $\mathrm{C}$ ). This is consistent with our previous observations on the effects of $A_{2 A} R$ stimulation on the in vitro cytotoxic function of OVA-specific OT-I T cells (33). To confirm that the effect of NECA on cytokine production was mediated through the $A_{2 A} R$, we next measured the levels of IFN- $\gamma$ and TNF- $\alpha$ produced by WT or $\mathrm{A}_{2 \mathrm{~A}} \mathrm{R}^{-/-}$CAR $\mathrm{T}$ cells following antigen stimulation in the presence or absence of NECA. We found that the production of both IFN- $\gamma$ and TNF- $\alpha$ by anti-HER2 CAR T cells derived from $\mathrm{A}_{2 \mathrm{~A}} \mathrm{R}^{-/-}$mice was not modulated by NECA, confirming the involvement of the $\mathrm{A}_{2 \mathrm{~A}} \mathrm{R}$ in this effect (Figure $1 \mathrm{~F}$ ).

$A_{2 A} R^{-/}$CAR $T$ cells exhibit superior antitumor function in vivo. Given that our in vitro data indicated that CAR $\mathrm{T}$ cell function was negatively modulated by $\mathrm{A}_{2 \mathrm{~A}} \mathrm{R}$ stimulation, we next assessed the impact of targeting $A_{2 A} R$ on CAR $T$ cell activity in vivo. CAR $\mathrm{T}$ cell function was tested using the 24JK-HER2 and E0771-HER2 lines, both of which expressed CD73 (Supplemental Figure 2B). Using WT or $\mathrm{A}_{2 \mathrm{~A}} \mathrm{R}^{-/}$donor $\mathrm{T}$ cells transduced with the anti-HER2 CAR, we found that adoptive transfer of $A_{2 A} R^{-/}$CAR $T$ cells had significantly greater activity against established subcutaneous 24JK-HER2 tumors (Figure 2A and Supplemental Figure 5A) or E0771-HER2 tumors injected orthotopically in the mammary fat pad of HER2 recipient mice (Figure 2B). Importantly, WT and $\mathrm{A}_{2 \mathrm{~A}} \mathrm{R}^{-/-} \mathrm{T}$ cells showed equivalent expression of the CAR and similar phenotype in terms of $\mathrm{CD}^{+}$and $\mathrm{CD} 8^{+}$frequency, indicating that the differences in antitumor efficacy were not due to transduction efficiency (Supplemental Figure 1). Since we have previously shown that $A_{2 A} R$ blockade enhances anti-PD-1 activity (33) and that anti-PD-1 enhances the efficacy of CAR T cells (16), we next investigated the potential of concomitantly targeting both immunosuppressive pathways. Blockade of PD-1 in in vitro cocultures of anti-HER2 CAR T cells with 24JK-HER2 target cells was shown to enhance $A 2 a R$ expression (Figure $2 \mathrm{C}$ ), suggesting that enhanced $A_{2 A}$ R expression could limit the efficacy of CAR T cells treated with anti-PD-1. Therefore we investigated the efficacy of CAR T cells derived from WT or $\mathrm{A}_{2 \mathrm{~A}} \mathrm{R}^{-/-}$splenocytes in mice bearing established E0771-HER2 tumors and treated with either anti$\mathrm{PD}-1$ or isotype control. Strikingly, mice treated with $\mathrm{A}_{2 \mathrm{~A}} \mathrm{R}^{-/-} \mathrm{CAR}$ $\mathrm{T}$ cells and anti-PD-1 showed significantly greater therapeutic responses (Figure 2D and Supplemental Figure 5B), resulting in a significant survival advantage in mice treated with this combination $(40 \%)$ compared with mice treated with WT CAR T cells and anti-PD-1 ( 15\%) (Figure 2E). In a further experiment we compared the level of $\mathrm{A}_{2 \mathrm{~A}} \mathrm{R}$ expressed on Ly5.1 $1^{+}$congenically marked $\mathrm{CD}^{+}$CAR T cells and endogenous CD $45.2^{+} \mathrm{CD}^{+} \mathrm{T}$ cells derived from the tumor and spleen at day 9 following adoptive transfer. We found that $A 2 a R$ expression was significantly increased in CAR T cells isolated from E0771-HER2 tumors compared with either CAR T cells taken from the spleen or endogenous CD8 ${ }^{+} \mathrm{T}$ cells from the spleen or tumor (Figure $2 \mathrm{~F}$ ). These data suggested that antigen-specific stimulation of CAR T cells in vivo induced upregulation of $A_{2 A} R$ expressed on these cells and that pharmacological blockade of the $A_{2 A} R$ pathway may enhance the activity of gene-modified $\mathrm{T}$ cells directed against HER2 ${ }^{+}$tumors.
$A_{2 A} R$ blockade combined with anti-PD-1 leads to stronger antitumor effects of CAR T cells. To investigate the potential of $\mathrm{A}_{2 \mathrm{~A}} \mathrm{R}$ targeting in a translationally relevant setting, we next tested the ability of the $A_{2 A} R$ antagonist SCH58261 to enhance the therapeutic activity of CAR T cells either alone or in the context of PD-1 blockade. Interestingly, we found that although SCH58261 had little effect on CAR T cell activity against established 24JK-HER2 (Figure 3A) or E0771-HER2 tumors (Figure 3B) when administered alone with CAR $T$ cells, the $A_{2 A} R$ antagonist significantly enhanced the activity of CAR T cells when combined with PD-1 blockade, resulting in greater tumor growth inhibition (Figure 3, A and B, and Supplemental Figure 5, C and D) and significantly increased survival of mice (Figure $3 \mathrm{C}$ ). This increased efficacy of CAR T cells was significantly greater than that seen with antiPD-1 alone. This result was confirmed using an alternative $A_{2 A} R$ antagonist, ZM241385, confirming the involvement of the $A_{2 A} R$ (Figure 3D). Coblockade of both $\mathrm{A}_{2 \mathrm{~A}} \mathrm{R}$ and PD-1 pathways in combination with anti-HER2 CAR T cells was critical for this enhanced antitumor effect, given that neither SCH58261, anti-PD-1, nor the combination modulated tumor growth in the absence of CAR T cells (Supplemental Figure 6). In summary, our data demonstrate that dual blockade of PD-1 and $\mathrm{A}_{2 \mathrm{~A}} \mathrm{R}$ pathways could significantly enhance CAR T cell activity.

Treatment with CAR T cells and dual blockade of $A_{2 A} R$ and $P D-1$ pathways does not cause autoimmunity in tumor-bearing mice. We have previously reported that the human HER2 antigen is expressed as a self-antigen in the brain (cerebellum) and mammary tissue of HER2 transgenic mice (36). In this model we have previously demonstrated that transfer of CAR T cells directed against the HER2 antigen in combination with anti-PD-1 did not induce pathology to HER2+ tissue (16). This is likely due to the lower level of HER2 expression found on healthy tissues compared with the tumor cells in this model (36). However, given the significant increase in therapeutic responses observed in our model following CAR T cell transfer and $\mathrm{A}_{2 \mathrm{~A}} \mathrm{R} / \mathrm{PD}-1$ blockade, it remained possible that the combined therapy may have resulted in some level of pathology against normal antigen-positive tissue. Therefore we performed H\&E staining of brain and mammary sections from HER2 transgenic mice that were preconditioned and challenged with HER2 ${ }^{+}$E0771 tumor before receiving anti-HER2 CAR T cells alone or in combination with antiPD-1 and the $A_{2 A} R$ antagonist SCH58261. We also assessed mammary and brain tissue from cohorts of mice treated with $A_{2 A} R^{-/-}$or WT CAR T cells combined with anti-PD-1. All sections were closely assessed for inflammation potentially induced by increased infiltration of $\mathrm{T}$ cells. We observed no evidence of pathology in either brain or mammary tissue from mice treated with anti-HER2 CAR T cells in combination with SCH58261 and anti-PD-1 antibody (Figure 3E) or with $\mathrm{A}_{2 \mathrm{~A}} \mathrm{R}^{-/-}$CAR T cells and anti-PD-1 (data not shown). Therefore the data importantly demonstrate that the functional activity of CAR T cells can be significantly increased, leading to improving therapeutic antitumor responses in the absence of toxicity to normal antigen-expressing tissue.

Dual targeting of PD-1 and $A_{2 A} R$ pathways enhances cytokine production by CAR $T$ cells in vivo. We next investigated whether the increased therapeutic effects associated with concomitant blockade of the PD- 1 and $\mathrm{A}_{2 \mathrm{~A}} \mathrm{R}$ pathways correlated with increased function and/or localization of CAR T cells to the tumor site. In 


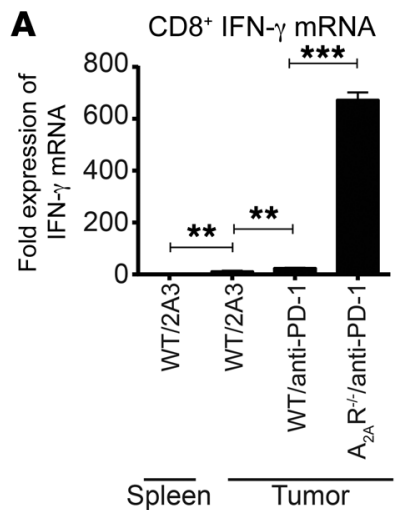

B

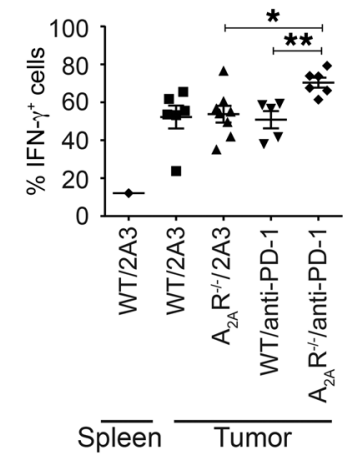

$\mathrm{CD} 8^{+} \mathrm{ICS}$

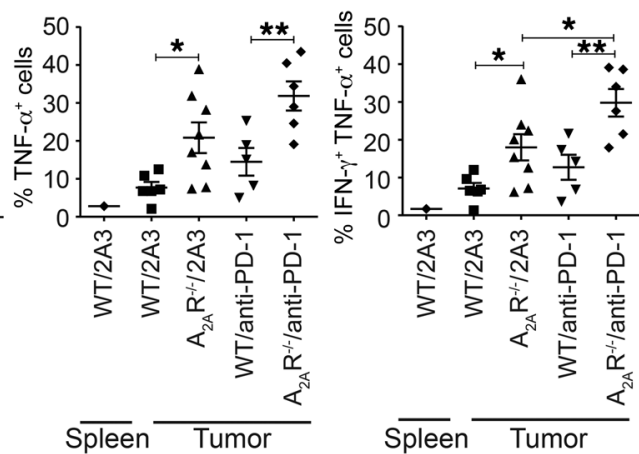

C

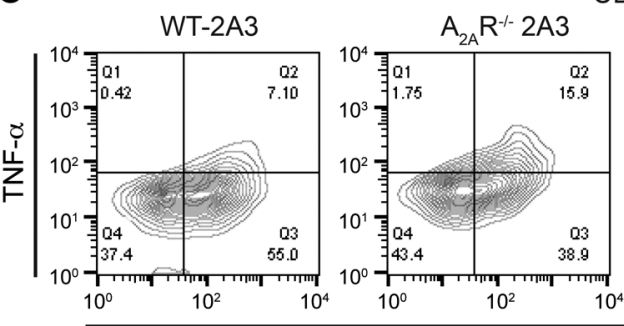

CD8 ${ }^{+}$ICS

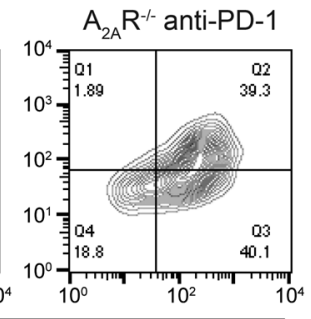

IFN- $\gamma$
D

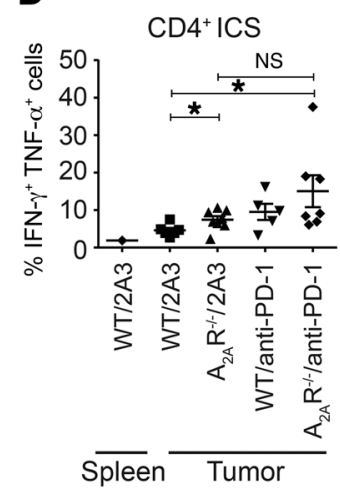

E Spleen analysis-Phenotype

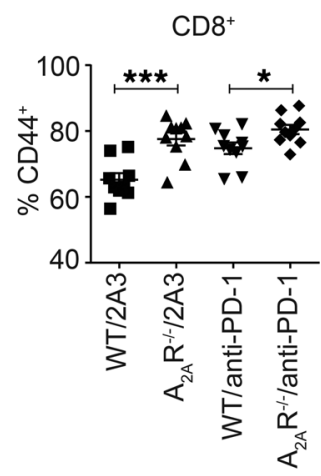

F Spleen analysis-Cell numbers

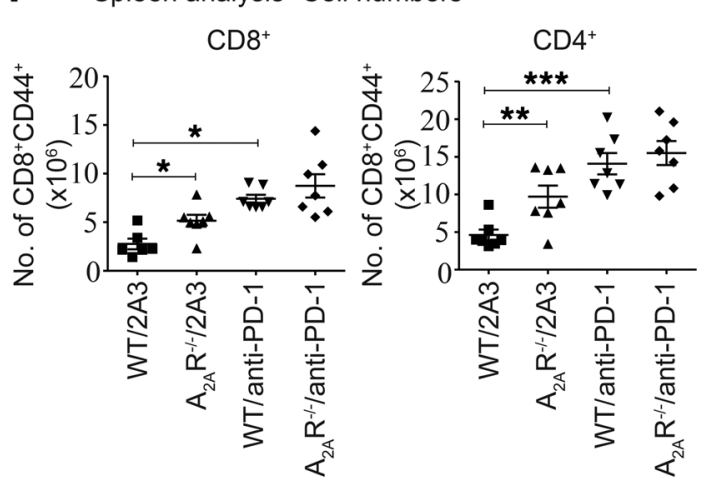

Figure 4. $A_{2 A} R^{-/-}$CD8+ CAR T cells exhibit enhanced cytokine production in vivo when combined with PD-1 blockade. C57BL/6-HER2 mice were injected with $1 \times 10^{5}$ E0771-HER2 tumor cells and treated per Figure 2. On day 6 after T cell injection, TILs and splenocytes were isolated. (A) CD45.2+CD3+CD8 ${ }^{+}$T cells were FACS sorted 6 days after injection and lysed. IFN- $g$ mRNA was determined by qPCR. Data are expressed relative to IFN- $g$ mRNA content of splenic CD8 ${ }^{+}$T cells. Samples from 3-5 mice were pooled, and qPCR was run in triplicate. (B) TILs were restimulated with PMA (20 ng/ml) and ionomycin (1 $\left.\mu \mathrm{g} / \mathrm{ml}\right)$ for 3 hours in the presence of GolgiPlug/GolgiStop. (B-D) Proportion of $\mathrm{CD3}^{+} \mathrm{CD} 8^{+}$(B and $\mathbf{C}$ ) or $\mathrm{CDB}^{+} \mathrm{CD} 4^{+}$(D) cells that were IFN- $\gamma^{+}$, TNF- $\alpha^{+}$, or IFN- $\gamma^{+} T N F-\alpha^{+}$. ICS, intracellular cytokine staining. (C) Representative FACS plots gated on $\mathrm{CD3}^{+} \mathrm{CD} 8^{+}$TILs. (E and $\left.\mathbf{F}\right)$ Proportion (E) and absolute number (F) of splenic CD8 ${ }^{+}$ or CD4+ cells expressing CD44. (B, D, E, and F) Data are shown as the mean \pm SEM for at least 5 mice. ${ }^{*} P<0.05,{ }^{* *} P<0.01,{ }^{* * *} P<0.001$ by 1 -way ANOVA.

these experiments we transferred either WT or $\mathrm{A}_{2 \mathrm{~A}} \mathrm{R}^{-/-}$anti-HER2 CAR T cells and examined the phenotype and function of tumorinfiltrating CAR T cells, including their cytokine production, frequency, and expression of the proliferative marker Ki-67. Most notably, in the context of PD-1 blockade we observed significantly enhanced IFN- $\gamma$ produced by $\mathrm{CD}^{+} \mathrm{CAR} \mathrm{T}$ cells combined with anti-PD-1 compared with WT CAR T cells and anti-PD-1 as measured by direct ex vivo intracellular staining (Supplemental Figure 7, A and B). Neither TNF- $\alpha$ nor IL-2 could be detected from CAR $\mathrm{T}$ cells stained directly ex vivo (data not shown). Direct ex vivo intracellular cytokine staining (without restimulation of $\mathrm{T}$ cells) likely underestimates cytokine production, and so we further analyzed this facet of CAR T cells using the more sensitive technique of quantitative PCR (qPCR) on FACS-isolated CD8 ${ }^{+} \mathrm{T}$ cells. Strikingly, using this methodology, the increase in IFN-g mRNA was found to be even more highly significant $(P<0.01)$, with a more than 25-fold increase in IFN- $g$ mRNA in $\mathrm{A}_{2 \mathrm{~A}} \mathrm{R}^{-/-}$CAR T cells compared with WT controls (Figure 4A). To further assess the cytokine production of CAR T cells within the tumor microenvironment, we also analyzed their ability to produce IFN- $\gamma$, TNF- $\alpha$, and IL-2 following a brief restimulation with PMA and ionomycin. Using this methodology, a significant increase in the percentage of $\mathrm{CD} 8^{+}$ 
A

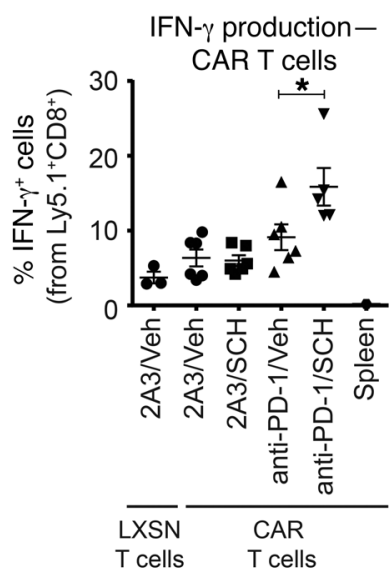

C

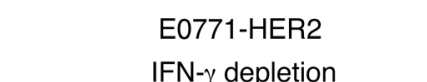

B

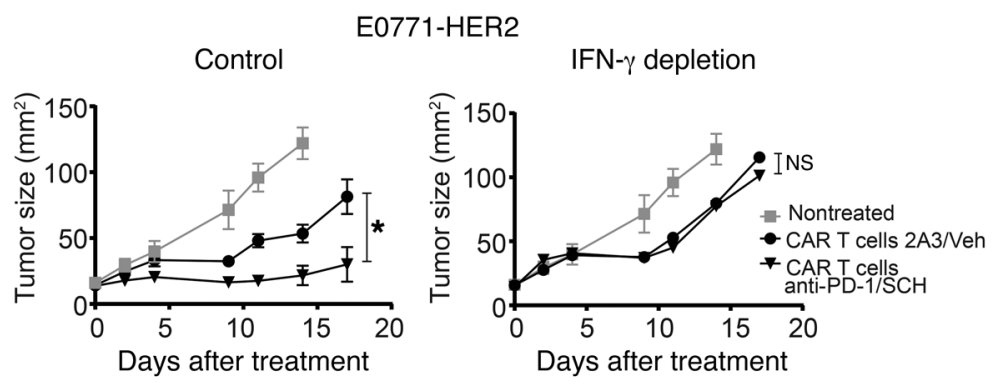

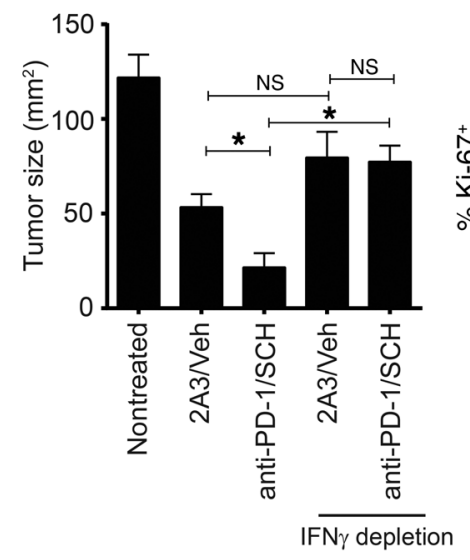

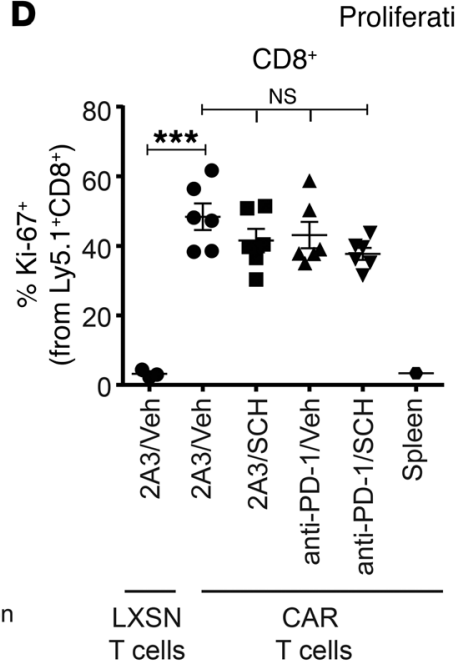

D $\begin{gathered}\text { E0771-HER2 } \\ \text { Proliferation-CAR T cells }\end{gathered}$

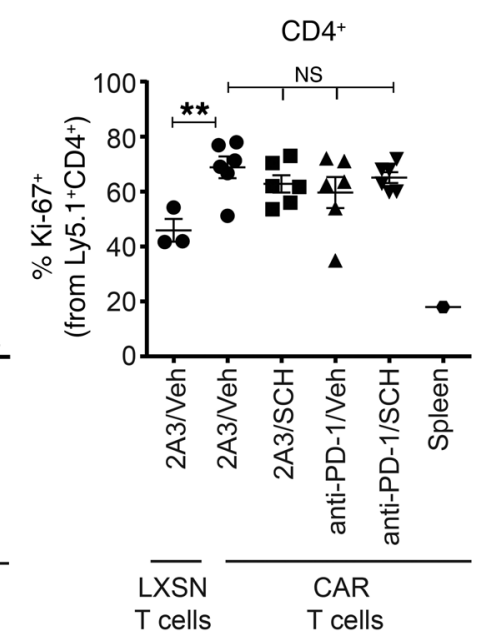

Figure 5. Combined $A_{2 A} R$ and PD-1 blockade enhances the antitumor efficacy of anti-HER2 CAR T cells by increasing CD8 ${ }^{+}$IFN- $\gamma$ production.

C57BL/6-HER2 mice were injected with E0771-HER2 tumor cells and treated with WT (B and C) or Ly5.1+ (A and D) CAR T cells, anti-PD-1 or 2A3, and SCH58261 or vehicle control per Figures 2 and 3. (B and $\mathbf{C})$ Where indicated, mice were also treated with anti-IFN- $\gamma(250 \mu \mathrm{g} / \mathrm{mouse})$ on days $0,1,4$, and 8 after T cell transfer. (C) Mean tumor size at day 14 is shown for each group. (B and $\mathbf{C}$ ) Data are shown as the mean \pm SEM for 5 mice per group from a representative experiment of $n=2$. (A and $\mathbf{D}$ ) Day 9 after T cell transfer, TILs were analyzed by FACS. (A) Proportion of CD3 $3^{+}$CD8 ${ }^{+}$cells that were IFN- $\gamma^{+}$. (D) Proportion of $\mathrm{CD}^{+}{ }^{+} \mathrm{CD} 8^{+}$or $\mathrm{CD} 3^{+} \mathrm{CD} 4^{+}$cells expressing Ki-67. (A and $\left.\mathbf{D}\right)$ Data are shown as the mean \pm SEM for at least 3 mice from a representative experiment of $n=3$. "LXSN T cells" refers to T cells transduced with the empty retroviral vector (LXSN) control. ${ }^{*} P<0.05,{ }^{* *} P<0.01,{ }^{* * *} P<0.001$ by 1-way ANOVA (A, C, and D) or 2-way ANOVA (B).

CAR T cells expressing IFN- $\gamma$ was observed in cells isolated from mice treated with $\mathrm{A}_{2 \mathrm{~A}} \mathrm{R}^{--}$CAR T cells and anti-PD-1 (Figure 4, $\mathrm{B}$ and $\mathrm{C}$ ), thus confirming our results obtained with cells stained directly ex vivo (Supplemental Figure 7, A and B). Strikingly, stimulation of the cells with PMA/ionomycin revealed that a significantly greater proportion of $\mathrm{A}_{2 \mathrm{~A}} \mathrm{R}^{-/-} \mathrm{CAR} \mathrm{T}$ cells produced $\mathrm{TNF}-\alpha$ compared with WT controls (Figure 4, B and C), and, importantly, the combination of $\mathrm{A}_{2 \mathrm{~A}} \mathrm{R}^{-/-}$CAR T cells and anti-PD-1 treatment resulted in a significantly greater proportion of IFN- $\gamma^{+} \mathrm{TNF}-\alpha^{+}$ double-positive $\mathrm{CD}^{+} \mathrm{CAR}$ T cells (Figure 4, B and C). Interestingly, analysis of the $\mathrm{CD} 4^{+} \mathrm{CAR} \mathrm{T}$ cell population revealed that $\mathrm{CD}^{+} \mathrm{A}_{2 \mathrm{~A}} \mathrm{R}^{-/-} \mathrm{CAR} \mathrm{T}$ cells also exhibited a significantly greater proportion of IFN- $\gamma^{+}$TNF- $\alpha^{+}$double-positive cells (Figure 4D). PD-1 blockade showed a trend to further enhance this phenomenon, although this was not statistically significant. Even in the presence of PMA/ionomycin stimulation we could not detect the production of IL-2 by CAR T cells ex vivo, in keeping with our earlier in vitro results (Supplemental Figure 3).

Interestingly, $\mathrm{A}_{2 \mathrm{~A}} \mathrm{R}^{-/} \mathrm{CAR}$ T cells were not found at increased proportion (Supplemental Figure 7C) or absolute cell number (data not shown) compared with WT CAR T cells, and differences in Ki-67 expression were not observed in either CD8 ${ }^{+}$ or $\mathrm{CD}^{+}{ }^{+}$Foxp3 $^{-}$subsets (Supplemental Figure 7D). Therefore the lack of $\mathrm{A}_{2 \mathrm{~A}} \mathrm{R}$ expression appeared to act predominantly by enhancing the activation of the CAR T cells, particularly in combination with anti-PD-1.

To further investigate the effect of $\mathrm{A}_{2 \mathrm{~A}} \mathrm{R}$ deficiency on CAR $\mathrm{T}$ cell responses in vivo, we investigated the frequency and phenotype of splenic CAR T cells in mice treated with WT or $\mathrm{A}_{2 \mathrm{~A}} \mathrm{R}^{-/-}$ anti-HER2 CAR T cells. 
A

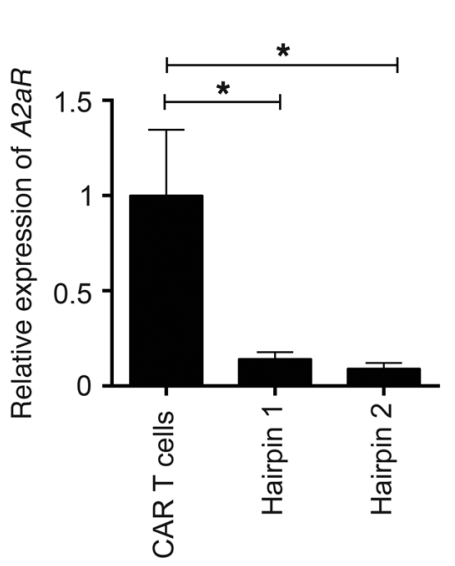

B

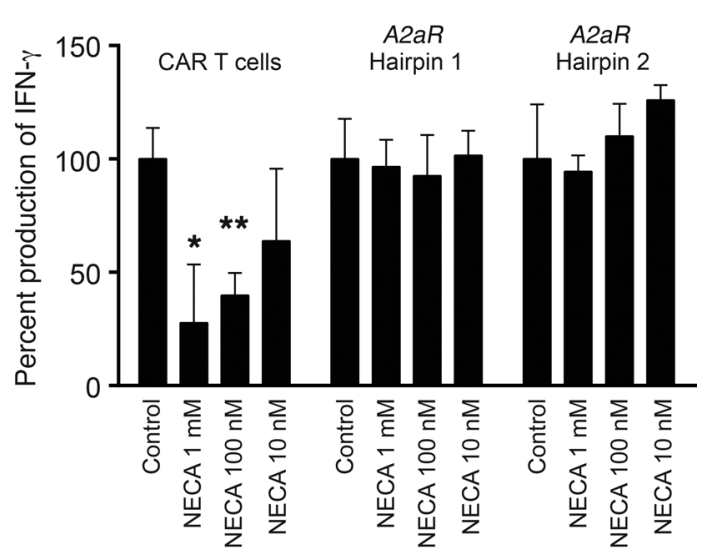

Figure 6. Targeting the $A_{2 A} R$ with shRNA retroviral technology enhances CAR T cell function. CAR $T$ cells were transduced with retroviruses encoding $A_{2 A} R$-directed shRNA or scrambled shRNA control and then selected with $2 \mu \mathrm{g} / \mathrm{ml}$ puromycin from day 4 to day 6 . Eight days after activation, CAR T cells were then assessed for function. (A) $1 \times 10^{6}$ CAR T cells were reactivated with plate-bound anti-CD3/ anti-CD28 $(0.5 \mu \mathrm{g} / \mathrm{ml})$ for 4 hours and then lysed for RNA analysis. Data are presented as the mean \pm SD of triplicates and expressed relative to the production of IFN- $\gamma$ of control cultures for each shRNAtransduced CAR T cell. (B) $1 \times 10^{5}$ CAR T cells were cocultured with 24JK/24JK-HER2 tumor cells at a 1:1 ratio in the presence or absence of NECA at indicated concentrations. Supernatants were collected after 16 hours and analyzed for concentration of IFN- $\gamma$. Data are presented relative to the IFN- $\gamma$ production of control cultures and as the mean \pm SD of quadruplicates from a representative experiment of $n=2 .{ }^{*} P<0.05,{ }^{* *} P<0.01$ by 1 -way ANOVA.

This revealed a significantly enhanced proportion (Figure $4 \mathrm{E}$ ) and absolute number (Figure $4 \mathrm{~F}$ ) of $\mathrm{CD} 44^{+}$cells in mice receiving $\mathrm{A}_{2 \mathrm{~A}} \mathrm{R}^{-/-}$CAR T cells. This was shown for both $\mathrm{CD} 8^{+}$and $\mathrm{CD} 4^{+} \mathrm{T}$ cell populations, suggesting that $A_{2 A} R$ activation limited the activation and expansion of both subsets. Notably, this supports our previous observation that $\mathrm{A}_{2 \mathrm{~A}} \mathrm{R}$ activation limits the activation of both $\mathrm{CD}^{+}$and $\mathrm{CD}^{+}$subsets in vitro (Supplemental Figure $3 \mathrm{~A}$ ) and in the tumor microenvironment (Figure 4, B-D).

We next examined CAR T cell phenotype following treatment of E0771-HER2 tumors in mice treated with anti-PD-1 and/or the $\mathrm{A}_{2 \mathrm{~A}} \mathrm{R}$ antagonist SCH58261. In these studies we used congenically marked Ly5.1 $1^{+}$CAR T cells to enable isolation and functional characterization of CAR T cells following transfer. Strikingly, we found that the combination of PD-1 and $A_{2 A} R$ blockade significantly enhanced IFN- $\gamma$ produced from $\mathrm{CD}^{+}$anti-HER2 CAR T cells (Figure 5A). This was a tumor-specific effect, given that there was negligible IFN- $\gamma$ detected from CAR T cells isolated from the spleen of treated mice. Blocking IFN- $\gamma$ activity using a neutralizing antibody revealed that the enhanced production of IFN- $\gamma$ by CAR T cells following anti-PD-1 and SCH58261 treatment was critical to the enhanced therapeutic efficacy observed (Figure 5B). Notably, in the context of IFN- $\gamma$ neutralization, the combination of antiHER2 CAR T cells, anti-PD-1, and SCH58261 did not result in any greater inhibition of tumor growth compared with anti-HER2 CAR $\mathrm{T}$ cells alone (Figure 5, B and C). Therefore, the benefit of dual PD-1/A ${ }_{2 A}$ R blockade was totally abrogated by IFN- $\gamma$ depletion.

Interestingly, we found that although the overall frequency of CAR T cells (both $\mathrm{CD}^{+} \mathrm{CAR}$ and $\mathrm{CD} 4^{+} \mathrm{CAR} \mathrm{T}$ cells) at the tumor site was significantly increased compared with control LXSN T cells following adoptive transfer, combined PD-1/ $A_{2 A} R$ blockade

had no additional effect on CAR T cell frequency (Supplemental Figure 8). This was also the case for expression of the proliferative marker Ki-67 (Figure 5D). We also analyzed the effect of combination therapy on the tumor-infiltrating host-derived $\left(\mathrm{CD} 45.2^{+}\right) \mathrm{T}$ cells. This analysis revealed that although PD-1 blockade enhanced the frequency of endogenous $\mathrm{CD}^{+} \mathrm{T}$ cells, this was not further increased by $A_{2 A} R$ blockade (Supplemental Figure 9A). Interestingly, the combination therapy showed a trend to increase IFN- $\gamma$ production by CD $45.2^{+} \mathrm{CD}^{+}$and CD $45.2^{+} \mathrm{CD}^{+}{ }^{+} \mathrm{Foxp}^{-} \mathrm{T}^{-}$ cells, although this was not statistically significant (Supplemental Figure 9B). We also did not observe any significant enhancement of the expression of the proliferation marker Ki-67 (Supplemental Figure 9C) in endogenous $\left(\mathrm{CD} 45.2^{+}\right) \mathrm{CD}^{+}$or $\mathrm{CD}^{+}$ $\mathrm{T}$ cells. Overall, the data strongly suggest that the increased therapeutic effects observed in the HER2 ${ }^{+}$tumor models following $\mathrm{A}_{2 \mathrm{~A}} \mathrm{R}$ targeting are predominantly due to enhanced CAR $\mathrm{T}$ cell activation including increased IFN- $\gamma$ production following antigen stimulation.

Genetic targeting of $A_{2 A} R$ protects $C A R T$ cells from adenosinemediated immunosuppression. Given the superior antitumor function of CAR $T$ cells derived from $A_{2 A} R^{-/-}$mice, we next investigated whether $A_{2 A} R$ knockdown using a retroviral shRNA-driven approach could replicate this phenotype. This is a highly translational approach to reduce the expression of $\mathrm{A}_{2 \mathrm{~A}} \mathrm{R}$ in CAR $\mathrm{T}$ cells and thus augment their function. Using shRNAs directed against $A_{2 A} R$ in a retroviral vector, we dualtransduced $T$ cells with the anti-HER 2 CAR and $A_{2 A}$ R-directed shRNAs or a scrambled shRNA control. At day 4-6 after transduction we selected the transduced cells with $2 \mu \mathrm{g} / \mathrm{ml}$ puromycin, and at day 8 after transduction, anti-HER2 CAR T cells were harvested for mRNA analysis. Significant reduction in the level of $A 2 a R$ mRNA was observed using 2 distinct $\mathrm{A}_{2 \mathrm{~A}} \mathrm{R}$ targeting shRNAs (Figure 6A). We then investigated the effect of $A_{2 A} R$ knockdown on the function of CAR $T$ cells. Having previously shown that $A_{2 A} R$ activation significantly suppressed CAR T cell IFN- $\gamma$ production upon coculture with HER2expressing tumor targets (Figure 1), we assessed the effect of NECA on the ability of CAR T cells to produce IFN- $\gamma$ following coculture with 24JK-HER2 tumor cells. As expected, NECA significantly inhibited the production of IFN- $\gamma$ of CAR T cells transduced with a scrambled shRNA (Figure 6B and Supplemental Figure 10). However, NECA no longer suppressed CAR $T$ cells transduced with either of the 2 hairpins directed against $A 2 a R$ (Figure 6B and Supplemental Figure 10). This result was comparable with that of using CAR T cells derived from $A_{2 A} R^{-/-}$ mice (Figure 1) and indicates that knockdown of $A_{2 A} R$ is a viable therapeutic strategy to replicate the enhanced antitumor function of $\mathrm{A}_{2 \mathrm{~A}} \mathrm{R}^{-/-}$CAR T cells. 
A

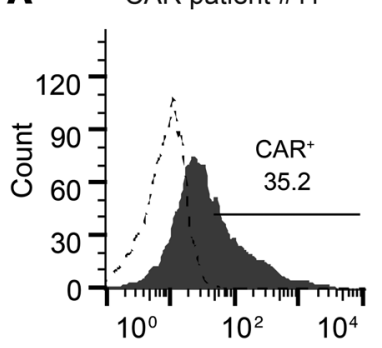

Tag (anti-HER2 CAR)

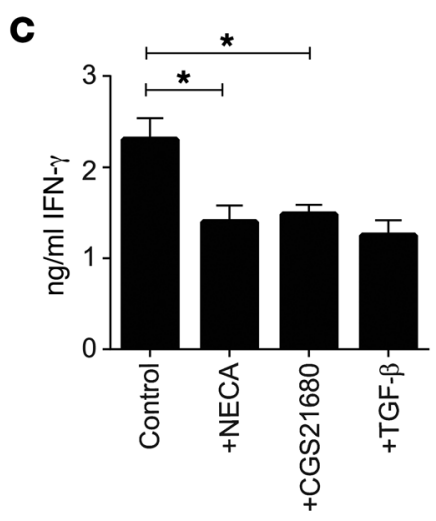

B

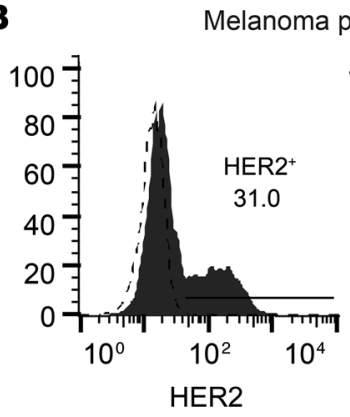

D

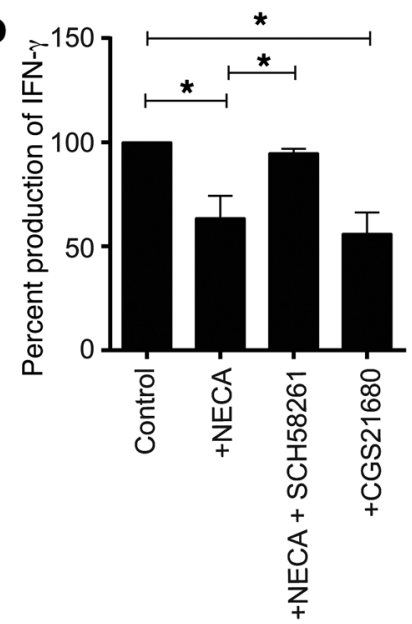

Figure 7. $A_{2 A} R$ blockade enhances the activity of patient-derived CAR $T$ cells against HER2-expressing autologous melanocytes. (A) Expression of anti-HER2 CAR on patient-derived CAR T cells. (B) Expression of HER2 and CD73 on primary melanoma samples used as targets in coculture assays. Dashed histograms indicate isotype control staining. (C and D) $2 \times 10^{5}$ human anti-HER2 CAR T cells were cocultured with $1 \times 10^{5}$ autologous primary-derived melanocytes in the presence of NECA $(1 \mu \mathrm{M})$, SCH58261 (1 $\mu \mathrm{M})$, CGS21680 $(10 \mu \mathrm{M})$, or TCF- $\beta(10 \mathrm{ng} / \mathrm{ml})$ where indicated. After 16 hours, supernatants were analyzed for IFN- $\gamma$ content by cytometric bead array. (A-C) Data are shown from a representative patient of $n=4$. (C) Data are the mean \pm SD of triplicates. (D) Data are pooled from 4 individual patients and are shown as percentage IFN- $\gamma$ production normalized to control cultures in each experiment. ${ }^{*} P<0.05$ by 1 -way ANOVA.
$A_{2 A} R$ blockade enhances the activity of patient-derived CAR T cells. To confirm that the $\mathrm{A}_{2 \mathrm{~A}}$ Rimmunosuppressive pathway was relevant to human CAR T cells, we cocultured patient-derived anti-HER2 CAR T cells with autologous melanoma-derived tumor cells. Patient-derived CAR T cells showed high expression of the anti-HER2 CAR (Figure 7A), and melanoma tumor cells were found to express HER2 (Figure 7B). Notably, 3 of 4 primary melanomas tested showed high expression of CD73 (Figure 7B and Supplemental Figure 11), underlining the importance of the adenosine immunosuppressive pathway in cancer patients. We assessed the importance of $\mathrm{A}_{2 \mathrm{~A}} \mathrm{R}$ activation on human CAR $T$ cells by performing cocultures in the presence or absence of NECA or the $A_{2 \mathrm{~A}} \mathrm{R}$-specific agonist CGS21680. IFN- $\gamma$ production by CAR T cells was significantly inhibited by both NECA and CGS21680 in this setting (Figure 7, $C$ and $D$ ) and was rescued by the $A_{2 A} R$ antagonist SCH58261 (Figure 7D), confirming the importance of this pathway for human CAR T cells. The level of suppression was equivalent to that achieved with TGF- $\beta$, a potently immunosuppressive cytokine, highlighting the magnitude of suppression mediated by the $A_{2 A} R$. These data strongly suggest that $\mathrm{A}_{2 \mathrm{~A}} \mathrm{R}$-mediated immunosuppression limits the efficacy of CAR T cells in patients and is a therapeutic target with high translational potential.

\section{Discussion}

Adenosine-mediated immunosuppression is rapidly emerging as an important "checkpoint inhibitor" of antitumor T cell immune responses (30). Studies by our group and others have shown that blockade of $\mathrm{A}_{2 \mathrm{~A}}$ Rs or inhibition of the ectoenzymes CD39 and CD73 can stimulate antitumor immune responses (18, 23, 24, 27, 31-33,
37). As a result of this preclinical work, several pharmaceutical companies have now developed $A_{2 A} R$ antagonists for use in oncology, with the first clinical trials being initiated (NCT02655822) (38). The ectoenzymes CD73 and CD39, which catalyze the conversion of ATP into adenosine, are overexpressed in several cancer types (19). Although the association between CD73/CD39 expression and patient prognosis is complex (39), in many cases the expression of CD73 has been shown to negatively correlate with patient survival. This includes patient cohorts in breast (20), ovarian (22), renal cell (40), rectal adenocarcinoma (41), and prostate cancer (42). Furthermore, targeting this pathway has been shown to enhance clinical responses to chemotherapy (20) and other classes of immunotherapy $(33,43,44)$. In the current study we explored the possibility that targeting the $\mathrm{A}_{2 \mathrm{~A}} \mathrm{R}$ could enhance CAR T cell activity. We used CAR $\mathrm{T}$ cells targeting human HER2 in transgenic mice engineered to endogenously express human HER2. This allowed us to assess both antitumor activity and potential pathology against normal HER2expressing tissues. This is relevant given the lethal toxicity observed in 1 patient treated with anti-HER2 CAR T cells (45). Although the HER2 transgenic model used in this study does not model the pulmonary toxicity observed in this patient, it provides proof of principle that targeting $A_{2 A} R$ does not increase CAR $T$ cell responses against HER2 ${ }^{+}$healthy tissues. Furthermore, a subsequent trial targeting HER2 using lower doses of CAR T cells in a larger cohort of patients reported no severe toxicity (46).

Our investigations revealed that $A_{2 A} R$ is upregulated following stimulation of the CAR to an extent similar to that observed with TCR activation. Although the signaling pathways control- 
ling $\mathrm{A}_{2 \mathrm{~A}} \mathrm{R}$ expression have not been fully defined, it has previously been shown that it is upregulated rapidly after TCR activation and is NFAT dependent (47). The A2AR gene also has putative binding sites for AP-1, NF1, and AP-4, although the role for these transcription factors in $\mathrm{A}_{2 \mathrm{~A}} \mathrm{R}$ expression has not been formally demonstrated (48). Our current study shows that the signaling pathway mediating $A_{2 A} R$ upregulation is engaged by the widely used second-generation CAR containing the signaling domains for $\mathrm{CD} 3$ and $\mathrm{CD} 28$, therefore providing the rationale to investigate whether $\mathrm{A}_{2 \mathrm{~A}} \mathrm{R}$ blockade could enhance CAR $\mathrm{T}$ cell activation. Further studies revealed that $A_{2 A} R$ activation suppressed cytokine production by CAR T cells in vitro but, interestingly, did not appear to modulate cytotoxic function of CAR T cells. This is consistent with our previous observations regarding $\mathrm{A}_{2 \mathrm{~A}} \mathrm{R}$ activation of OT-I T cells cocultured with OVA-expressing tumor cells (33). In this study we observed that although OT-I cytotoxic function was not improved by $\mathrm{A}_{2 \mathrm{~A}} \mathrm{R}$ blockade in vitro, treatment of mice with the $A_{2 A} R$ antagonist SCH58261 increased the expression of granzyme $\mathrm{B}$ in tumor-infiltrating $\mathrm{CD}^{+} \mathrm{T}$ cells in vivo. Although we were unable to detect changes in the expression of granzyme $\mathrm{B}$ in this study (data not shown), this is likely to be a result of the in vitro activation protocol required to generate CAR T cells, which results in more than $90 \%$ of $\mathrm{CD}^{+}$CAR T cells being granzyme $\mathrm{B}^{+}$. It therefore remains possible that $\mathrm{A}_{2 \mathrm{~A}} \mathrm{R}$ blockade enhances cytotoxic activity of CAR T cells in vivo.

Our studies showed that CAR $T$ cells derived from $\mathrm{A}_{2 \mathrm{~A}} \mathrm{R}^{-/-}$mice exhibit increased potency compared with WT controls. The magnitude of this phenotype was greater than that observed using 2 distinct $\mathrm{A}_{2 \mathrm{~A}} \mathrm{R}$ antagonists (SCH58261 or ZM241385) in combination with WT CAR T cells. The reasons for this are not fully understood but may relate to incomplete blockade of $\mathrm{A}_{2 \mathrm{~A}} \mathrm{Rs}$ achieved by pharmacological blockade in our studies. Although we achieved superior efficacy by increasing the dose of SCH58261 to $5 \mathrm{mg} / \mathrm{kg}$ twice daily, the antitumor response remained less marked than using $A_{2 A} R^{-/-}$CAR T cells (data not shown). While higher dosing of $A_{2 A} R$ antagonists is achievable using $A_{2 A} R$ compounds in clinical trials such as SYN-115 and CPI-444, $\mathrm{A}_{2 \mathrm{~A}} \mathrm{R}$ knockdown may represent an alternative or complementary method to enhance CAR $\mathrm{T}$ cell function. Indeed, our experiments with $\mathrm{A}_{2 \mathrm{~A}} \mathrm{R}$-targeting shRNA highlight the potential for $A_{2 A} R$ knockdown to enhance CAR T cell function. These data were generated using transiently transfected HEK293gp cells to produce retrovirus. Therefore we are currently unable to generate sufficient CAR T cells to perform an in vivo analysis. Nevertheless, these proof-of-principle studies highlight the potential for $A_{2 A} R$ knockdown strategies to enhance CAR T cell function in patients.

With either pharmacological blockade or genetic deficiency of $A_{2 A} R$, the phenotype observed was significantly greater when $A_{2 A} R$ targeting was combined with PD-1 blockade. This is consistent with our previous observations using the combination of anti-PD-1 and SCH58261 to significantly enhance endogenous antitumor $\mathrm{T}$ cell responses (33). In this previous study we found that PD-1 blockade enhanced $\mathrm{A}_{2 \mathrm{~A}}$ R expression on tumor-infiltrating $\mathrm{CD} 8^{+} \mathrm{T}$ cells, making them more susceptible to $A_{2 A} R$-mediated suppression. Similarly, in the current study we observed that PD-1 blockade enhanced $A_{2 A} R$ expression on CAR T cells. Therefore it is likely that this mechanism contributes to the increased efficacy of the combination of PD- 1 and $\mathrm{A}_{2 \mathrm{~A}} \mathrm{R}$ blockade in the context of CAR $\mathrm{T}$ cell therapy.
Interestingly, we observed that $\mathrm{A}_{2 \mathrm{~A}} \mathrm{R}$ targeting enhanced the cytokine production of $\mathrm{CD}^{+} \mathrm{CAR} \mathrm{T}$ cells both in vitro and in vivo. Most striking effects were seen on the production of IFN- $\gamma$ following dual targeting of PD- 1 and the $A_{2 A} R$, particularly given that the efficacy of the combination therapy was abrogated in the context of IFN- $\gamma$ neutralization. This result is consistent with recent reports indicating that the efficacy of checkpoint inhibitors in patients is dependent on IFN- $\gamma$ signaling (49-51). Our studies also revealed that $A_{2 A} R$-deficient CAR T cells exhibited increased secretion of TNF- $\alpha$ within the tumor microenvironment. The reasons for this remain to be elucidated but could be related to the observation that the $\mathrm{CAMP} / \mathrm{PKA}$ pathway (the predominant signaling pathway for the $A_{2 A} R$ ) potently inhibits TNF- $\alpha$ production in macrophages (52). Although our results indicate that increased IFN- $\gamma$ production is critical for the efficacy of dual PD- $1 / A_{2 A} R$ targeting, this does not preclude a role for TNF- $\alpha$ in this effect given that TNF- $\alpha$ may act in part to increase IFN- $\gamma$ production.

Notably, the cytokine production of $\mathrm{CD} 4^{+} \mathrm{CAR} \mathrm{T}$ cells were also enhanced by $A_{2 A} R$ blockade. This is potentially important given the previous reports indicating that $\mathrm{CD} 4^{+} \mathrm{CAR} T$ cells can significantly enhance overall CAR T cell efficacy (53-55). Hence, targeting $\mathrm{A}_{2 \mathrm{~A}} \mathrm{R}$ may enhance CAR $\mathrm{T}$ cell activity in part through augmenting $\mathrm{CD}^{+}$CAR $\mathrm{T}$ cell responses. Notably, in contrast to conventional $\mathrm{CD} 4^{+} \mathrm{T}$ cells, CAR $\mathrm{CD} 4^{+} \mathrm{T}$ cells have the capacity to be activated by tumor cells directly owing to robust tumorantigen recognition through the CAR. This is supported by the fact that $\mathrm{CD} 4^{+} \mathrm{CAR} \mathrm{T}$ cells produce cytokines directly upon coculture with tumor cells whereas OT-II cells are unable to produce cytokines when cocultured with OVA-expressing tumor cells (our unpublished observations). This difference in terms of activation requirements may be important in terms of adenosine-mediated immunosuppression, since concentrations of adenosine are greatest locally within the tumor (18), and so $\mathrm{CD}^{+}$CAR T cells may be more susceptible to adenosine-mediated immunosuppression than endogenous $\mathrm{CD} 4^{+} \mathrm{T}$ cells. It has previously been shown that stimulation of $\mathrm{A}_{2 \mathrm{~A}} \mathrm{R}$ on $\mathrm{CD} 4^{+} \mathrm{T}$ cells can promote generation of a Treg phenotype $(56,57)$ and suppress a CD4-mediated graftversus-host disease colitis response (58), but relatively little is known about the effect of $\mathrm{A}_{2 \mathrm{~A}} \mathrm{R}$ stimulation on $\mathrm{CD}^{+}{ }^{+}$Foxp3 ${ }^{-}$cells within the tumor microenvironment.

In summary, this study has highlighted the potential of targeting $A_{2 A} R$-mediated suppression to enhance the activity of CAR T cells, particularly against solid tumors, where the activity of CAR T cells has so far been less impressive and where adenosine-mediated immunosuppression is more prevalent due to the hypoxic environment. This is a highly translational approach, since antagonists for $\mathrm{A}_{2 \mathrm{~A}} \mathrm{R}$ have undergone phase III clinical trials for Parkinson's disease and are currently in phase I trials in oncology. Given the increased activity of $\mathrm{A}_{2 \mathrm{~A}} \mathrm{R}^{-/-}$CAR T cells and our in vitro data with CAR T cells expressing shRNAs targeting the $A_{2 A} R$, we propose that strategies designed to target $A_{2 A} R$ at the genetic level are of interest and may be the subject of further studies. Furthermore, given that our data indicate that the $A_{2 A} R$ pathway limits the activity of patient-derived CAR $T$ cells and the emergence and success of clinical trials combining adoptive cell transfer (ACT) with both anti-CTLA-4 $(59,60)$ and anti-PD-1 (NCTO2652455), we believe that clinical trials combining CAR $T$ cells and $\mathrm{A}_{2 \mathrm{~A}} \mathrm{R}$ blockade are warranted. 


\section{Methods}

Cell lines and mice. The C57BL/6 mouse breast carcinoma cell line E0771 (Robin Anderson, Peter MacCallum Cancer Centre) (61) and 24JK (Patrick Hwu, NIH, Bethesda, Maryland, USA) (62) were engineered to express truncated human HER2 as previously described (63). Tumor lines were also verified to be mycoplasma negative by Victorian Infectious Diseases Reference Laboratory (Melbourne, Victoria, Australia) by PCR analysis. Tumor cells were grown in RPMI supplemented with $10 \%$ FCS, 2 mM glutamine, $0.1 \mathrm{mM}$ nonessential amino acids (NEAA), HEPES, $1 \mathrm{mM}$ sodium pyruvate, and penicillin/ streptomycin. For in vivo experiments, the indicated number of cells were resuspended in PBS and injected subcutaneously in a $100-\mu \mathrm{l}$ volume (male mice; 24JK-HER2) or into the fourth mammary fat pad in a 20- $\mu$ l volume (female mice; E0771-HER2). C57BL/6 WT mice or C57BL/6 hHER2 mice were bred in house at the Peter MacCallum Cancer Centre. C57BL/6 A $\mathrm{A}_{2 \mathrm{~A}} \mathrm{R}^{-/-}$mice were bred at St Vincent's Hospital (Melbourne, Victoria, Australia). Ly5.1 mice used for the adoptive transfer of congenically marked $\mathrm{T}$ cells were purchased from the Walter and Eliza Hall Institute (Melbourne, Victoria, Australia). Mice were used between 6 and 16 weeks of age.

Antibodies, cytokines, agonists, and antagonists. SCH58261, ZM241385, and 5'-( $N$-ethylcarboxamido)adenosine (NECA) were purchased from Sigma-Aldrich. Antibodies to PD-1 (clone RMP1-14) or isotype control (clone 2A3) were purchased from BioXcell. For cell stimulation, anti-CD3 (clone 145-2C11) and anti-CD28 (clone 37.51) antibodies were purchased from BD Pharmingen and anti-myc tag (clone 2276) from Cell Signaling Technology. IL-2 and IL-7 used for T cell stimulation were obtained from the NIH and PeproTech, respectively.

Generation of murine CAR T cells. Retrovirus encoding a CAR composed of an extracellular ScFv-anti-human HER2 fused to the transmembrane domains of $\mathrm{CD} 28$ and $\mathrm{CD} 3 \zeta$ was obtained from the supernatant of the GP+E86 packaging line as previously described $(16,64$, 65). Splenocytes were cultured in RPMI supplemented with $10 \%$ FCS, glutamine, NEAA, sodium pyruvate, and penicillin/streptomycin. Activation was performed with anti-CD3 $(0.5 \mu \mathrm{g} / \mathrm{ml})$ and anti-CD28 $(0.5 \mu \mathrm{g} / \mathrm{ml})$ in the presence of $100 \mathrm{IU} / \mathrm{ml} \mathrm{IL}-2$ and $2 \mathrm{ng} / \mathrm{ml} \mathrm{IL-7} \mathrm{at} \mathrm{a}$ density of $5 \times 10^{6}$ per milliliter. After 24 hours, live T cells were isolated after a Ficoll centrifugation step. Four milliliters of retroviral supernatant was added to each well of retronectin-coated $(10 \mu \mathrm{g} / \mathrm{ml})$ 6-well plates (Takara Bio). After a 30-minute spin of virus onto retronectincoated plates $(1,200 \mathrm{~g})$, T cells were resuspended in $1 \mathrm{ml}$ of additional retroviral-containing supernatant supplemented with IL-2 and IL-7 and then added to the retronectin-coated plates to give a final volume of $5 \mathrm{ml} /$ well. Final $\mathrm{T}$ cell concentration was $5 \times 10^{6}$ to $10 \times 10^{6}$ per well. After a 90-minute spin, T cells were incubated overnight before repetition of the transduction process. T cells were maintained in IL-2- and IL-7-containing media and cells used at days 7-9 after transduction. LXSN control T cells were generated in the same way using a GP+E86 cell line transduced with an empty vector control (LXSN).

Generation of $A_{2 A} R$ knockdown CAR T cells. $2 \times 10^{6}$ HEK293gp cells were plated onto poly-D-lysine-treated $10-\mathrm{cm}^{2}$ dishes overnight and transfected the following day with $10 \mu \mathrm{g}$ pMD2.G, $4 \mu \mathrm{g}$ pcSUPERshDGCR8 (Luke Dow, Weill Cornell Medical College, New York, New York, USA) (66), and $20 \mu \mathrm{g}$ of $\mathrm{A}_{2 \mathrm{~A}}$ R-targeted shRNA plasmid (pRFPC-RS; Origene) using Lipofectamine 2000 (Invitrogen) per the manufacturer's instructions. Viral-containing supernatant was collected and filtered (0.45- $\mu \mathrm{m}$ filter) at days 2 and 3 after transfection and used to transduce murine splenocytes concurrently with the anti-HER2 CAR-encoding retrovirus. Three days after transduction, T cells were selected using $2 \mu \mathrm{g} / \mathrm{ml}$ puromycin.

Analysis of adenosine receptor expression by reverse transcriptase PCR. RNA was isolated from T lymphocytes using the Qiagen miRNA Easy Mini Kit per the manufacturer's instructions. cDNA was generated and qPCR analysis for $L 32, I F N-g$, and $A 2 a R$ was determined as previously described $(32,33)$.

Treatment of tumor-bearing mice. C57BL/6 human HER2 transgenic mice were injected subcutaneously with $1 \times 10^{6}$ 24JK-HER2 cells or subcutaneously/orthotopically with $1 \times 10^{5}$ E0771-HER2 cells. At day 7 after tumor injection, mice were preconditioned with totalbody irradiation ( $5 \mathrm{~Gy}$ ) prior to the administration of $1 \times 10^{7} \mathrm{CAR} \mathrm{T}$ cells on days 7 and 8 . Mice were also treated with 50,000 IU IL-2 on days $0-4$ after $\mathrm{T}$ cell transfer. Mice were treated with either isotype control (2A3) or anti-PD-1 (200 $\mu$ g per mouse) on days 0,4 , and 8 after $\mathrm{T}$ cell transfer and with $1 \mathrm{mg} / \mathrm{kg}$ SCH58261, $1 \mathrm{mg} / \mathrm{kg} \mathrm{ZM} 241385$, or vehicle control daily.

Analysis of tumor-infiltrating immune subsets. Tumors were excised and digested postmortem using a cocktail of $1 \mathrm{mg} / \mathrm{ml}$ collagenase type IV (Sigma-Aldrich) and $0.02 \mathrm{mg} / \mathrm{ml} \mathrm{DNase} \mathrm{(Sigma-Aldrich).} \mathrm{After}$ digestion at $37^{\circ} \mathrm{C}$ for 30 minutes, cells were passed through a $70-\mu \mathrm{m}$ filter twice. Cells were then analyzed for various functional parameters including cytokine production by flow cytometry directly ex vivo as previously described (32). In some experiments, isolated cells were restimulated with PMA (10 ng/ml) and ionomycin ( $1 \mu \mathrm{g} / \mathrm{ml}$; Sigma-Aldrich) in the presence of GolgiPlug and GolgiStop (BD Biosciences) for 4 hours before flow cytometry analysis.

Generation of human CAR T cells. Primary patient melanomas were resected, and 2- $\mathrm{mm}^{2}$ pieces of tissue were cultured in T cell media supplemented with $10 \%$ human serum (Valley Biomedical) and 6,000 IU/ $\mathrm{ml}$ IL-2 until T cells were expanded to $100 \times 10^{6}$ cells, at which point they were frozen down. After thawing, T cells were rested overnight in IL-2-containing media $(3,000 \mathrm{IU} / \mathrm{ml})$ and then stimulated with soluble anti-CD3 (OKT3; $30 \mathrm{ng} / \mathrm{ml}$ ) and 3,000 IU/ml IL-2 in the presence of irradiated (50 Gy) allogeneic feeder peripheral blood mononuclear cells. Six days after activation, T cells were transduced using supernatant from the packaging line PG13-anti-HER2 CD28/CD3ל as previously described (67). Transduction was performed as for mouse splenocytes but at a cell density of $2.5 \times 10^{6}$ per well in $5 \mathrm{ml}$ total volume. Transduced T cells were selected using G418 $(50 \mu \mathrm{g} / \mathrm{ml})$ and analyzed by flow cytometry day 5 after selection. T cells were maintained in IL-2-containing media $(600 \mathrm{IU} / \mathrm{ml})$ with further rounds of anti-CD3/ anti-CD28 stimulation used when required to increase $\mathrm{T}$ cell numbers.

Generation of matched primary melanoma cell lines. Tumor tissue was verified as melanoma in origin via positive staining for SOX10 and S100B. Tumors were digested in a mixture of $1 \mathrm{mg} / \mathrm{ml}$ collagenase type IV (Sigma-Aldrich), $0.02 \mathrm{mg} / \mathrm{ml}$ DNase (Sigma-Aldrich), and gentamicin $(10 \mu \mathrm{g} / \mathrm{ml})$. Primary melanoma cell lines were established in RPMI supplemented with 10\% FCS, GlutaMAX (Gibco), and penicillin/streptomycin, and, when necessary, passaged through NSG mice. Established melanoma lines were stained for S100B to reverify their status as melanomas.

Statistics. Statistical tests were performed as indicated in the figure legends with a $P$ value less than 0.05 considered significant.

Study approval. All animal studies were approved in advance by the Peter MacCallum Animal Ethics and Experimentation Commit- 
tee. Studies using patient samples were approved by the Peter MacCallum Human Ethics Research Committee, and all patients consented to the use of their tissues/peripheral blood for experimentation.

\section{Author contributions}

$\mathrm{PAB}$ and PKD designed the experiments and wrote the manuscript. PAB, MAH, LG, and PKD analyzed the data. PAB, MAH, LG, JKM, KS, AJD, LBJ, SM, CYS, and PKD performed the experiments. JKM and DG collected patient materials. MHK provided critical reagents. MAH, LG, RSC, RWJ, JAT, JS, SL, LK, DG, and MHK provided intellectual input and read the manuscript.

\section{Acknowledgments}

The authors acknowledge the assistance of the Animal Facility technicians at the Peter MacCallum Cancer Centre. This work was funded by Project and Program grants from the National Health and Medical Research Council (NHMRC; APP1062580, APP1122444), a Cancer Council Victoria Project Grant (APP1084420), and a grant from the Peter MacCallum Cancer Centre Foundation. PAB and CYS are supported by National Breast Cancer Foundation Fellowships (ID nos. PF-14-008 and ECF-16-005). PKD and MHK are supported by NHMRC Senior Research Fellowships (APP1041828 and APP1058388, respectively). RWJ is supported by a Senior Principal Research Fellowship from the NHMRC.

Address correspondence to: Paul A. Beavis or Phillip K. Darcy, Cancer Immunotherapy Laboratory, Victorian Comprehensive Cancer Centre, 305 Grattan Street, Melbourne, Victoria 3000, Australia. Phone: 613.85595051; E-mail: paula.beavis@petermac. org (PAB); phil.darcy@petermac.org (PKD).
1. Rosenberg SA, et al. Durable complete responses in heavily pretreated patients with metastatic melanoma using T-cell transfer immunotherapy. Clin Cancer Res. 2011;17(13):4550-4557.

2. Figlin RA, et al. Treatment of metastatic renal cell carcinoma with nephrectomy, interleukin-2 and cytokine-primed or $\mathrm{CD} 8(+)$ selected tumor infiltrating lymphocytes from primary tumor. JUrol. 1997;158(3 pt 1):740-745.

3. Quattrocchi KB, et al. Pilot study of local autologous tumor infiltrating lymphocytes for the treatment of recurrent malignant gliomas. J Neurooncol. 1999;45(2):141-157.

4. Morgan RA, et al. Cancer regression in patients after transfer of genetically engineered lymphocytes. Science. 2006;314(5796):126-129.

5. Eshhar Z, Waks T, Gross G, Schindler DG. Specific activation and targeting of cytotoxic lymphocytes through chimeric single chains consisting of antibody-binding domains and the gamma or zeta subunits of the immunoglobulin and T-cell receptors. Proc Natl Acad Sci U S A. 1993;90(2):720-724.

6. Finney HM, Lawson AD, Bebbington CR, Weir AN. Chimeric receptors providing both primary and costimulatory signaling in $\mathrm{T}$ cells from a single gene product. JImmunol. 1998;161(6):2791-2797.

7. Carpenito $C$, et al. Control of large, established tumor xenografts with genetically retargeted human $\mathrm{T}$ cells containing CD28 and CD137 domains. Proc Natl Acad Sci U S A. 2009;106(9):3360-3365.

8. Zhong XS, Matsushita M, Plotkin J, Riviere I, Sadelain M. Chimeric antigen receptors combining 4-1BB and CD28 signaling domains augment PI3kinase/AKT/Bcl-XL activation and $\mathrm{CD}^{+}$ $\mathrm{T}$ cell-mediated tumor eradication. Mol Ther. 2010;18(2):413-420.

9. Tammana S, et al. 4-1BB and CD28 signaling plays a synergistic role in redirecting umbilical cord blood T cells against B-cell malignancies. Hum Gene Ther. 2010;21(1):75-86.

10. Maude SL, et al. Chimeric antigen receptor $T$ cells for sustained remissions in leukemia. $N$ Engl JMed. 2014;371(16):1507-1517.

11. Kalos M, et al. $\mathrm{T}$ cells with chimeric antigen receptors have potent antitumor effects and can establish memory in patients with advanced leu- kemia. Sci Transl Med. 2011;3(95):95ra73.

12. Porter DL, Levine BL, Kalos M, Bagg A, June $\mathrm{CH}$. Chimeric antigen receptor-modified $\mathrm{T}$ cells in chronic lymphoid leukemia. N Engl J Med. 2011;365(8):725-733.

13. Kershaw MH, Westwood JA, Darcy PK. Geneengineered T cells for cancer therapy. Nat Rev Cancer. 2013;13(8):525-541.

14. Beavis PA, Slaney CY, Kershaw MH, Gyorki D, Neeson PJ, Darcy PK. Reprogramming the tumor microenvironment to enhance adoptive cellular therapy. Semin Immunol. 2016;28(1):64-72.

15. Beavis PA, Slaney CY, Kershaw MH, Neeson PJ, Darcy PK. Enhancing the efficacy of adoptive cellular therapy by targeting tumorinduced immunosuppression. Immunotherapy. 2015;7(5):499-512.

16. John LB, et al. Anti-PD-1 antibody therapy potently enhances the eradication of established tumors by gene-modified T cells. Clin Cancer Res 2013;19(20):5636-5646.

17. Liu X, et al. A chimeric switch-receptor targeting PD1 augments the efficacy of second-generation CAR T cells in advanced solid tumors. Cancer Res. 2016;76(6):1578-1590.

18. Ohta A, et al. A2A adenosine receptor protects tumors from antitumor T cells. Proc Natl Acad Sci U S A. 2006;103(35):13132-13137.

19. Beavis PA, Stagg J, Darcy PK, Smyth MJ. CD73: a potent suppressor of antitumor immune responses. Trends Immunol. 2012;33(5):231-237.

20. Loi S, et al. CD73 promotes anthracycline resistance and poor prognosis in triple negative breast cancer. Proc Natl Acad Sci U S A. 2013;110(27):11091-11096.

21. Leclerc BG, et al. CD73 Expression Is an Independent Prognostic Factor in Prostate Cancer. Clin Cancer Res. 2016;22(1):158-166.

22. Turcotte M, et al. CD73 is associated with poor prognosis in high-grade serous ovarian cancer. Cancer Res. 2015;75(21):4494-4503.

23. Stagg J, et al. Anti-CD73 antibody therapy inhibits breast tumor growth and metastasis. Proc Natl Acad Sci U S A. 2010;107(4):1547-1552.

24. Jin D, et al. CD73 on tumor cells impairs antitumor T-cell responses: a novel mechanism of tumor-induced immune suppression. Cancer Res. 2010;70(6):2245-2255.
25. Häusler SF, et al. Anti-CD39 and anti-CD73 antibodies A1 and 7G2 improve targeted therapy in ovarian cancer by blocking adenosinedependent immune evasion. Am J Transl Res. 2014;6(2):129-139.

26. Michaud M, et al. Autophagy-dependent anticancer immune responses induced by chemotherapeutic agents in mice. Science. 2011;334(6062):1573-1577.

27. Hatfield SM, et al. Immunological mechanisms of the antitumor effects of supplemental oxygenation. Sci Transl Med. 2015;7(277):277ra30.

28. Sitkovsky MV, Hatfield S, Abbott R, Belikoff B, Lukashev D, Ohta A. Hostile, hypoxiaA2-adenosinergic tumor biology as the next barrier to overcome for tumor immunologists. Cancer Immunol Res. 2014;2(7):598-605.

29. Sitkovsky MV, Kjaergaard J, Lukashev D, Ohta A. Hypoxia-adenosinergic immunosuppression: tumor protection by $\mathrm{T}$ regulatory cells and cancerous tissue hypoxia. Clin Cancer Res. 2008;14(19):5947-5952.

30. Leone RD, Lo YC, Powell JD. A2aR antagonists: Next generation checkpoint blockade for cancer immunotherapy. Comput Struct Biotechnol J. 2015;13:265-272.

31. Waickman AT, Alme A, Senaldi L, Zarek PE, Horton M, Powell JD. Enhancement of tumor immunotherapy by deletion of the A2A adenosine receptor. Cancer Immunol Immunother. 2012;61(6):917-926.

32. Beavis PA, et al. Blockade of A2A receptors potently suppresses the metastasis of CD73+ tumors. Proc Natl Acad Sci U S A. 2013;110(36):14711-14716.

33. Beavis PA, et al. Adenosine Receptor 2A blockade increases the efficacy of anti-PD-1 through enhanced antitumor T-cell responses. Cancer Immunol Res. 2015;3(5):506-517.

34. Hauser RA, et al. Tozadenant (SYN115) in patients with Parkinson's disease who have motor fluctuations on levodopa: a phase $2 b$, double-blind, randomised trial. Lancet Neurol. 2014;13(8):767-776.

35. Beavis PA, et al. CD73: A potential biomarker for anti-PD-1 therapy. Oncoimmunology. 2015;4(11):e1046675.

36. Wang LX, et al. Tumor ablation by gene-modified 
$\mathrm{T}$ cells in the absence of autoimmunity. Cancer Res. 2010;70(23):9591-9598.

37. Cekic C, Day YJ, Sag D, Linden J. Myeloid expression of adenosine A2A receptor suppresses $\mathrm{T}$ and NK cell responses in the solid tumor microenvironment. Cancer Res. 2014;74(24):7250-7259.

38. Allard B, Beavis PA, Darcy PK, Stagg J. Immunosuppressive activities of adenosine in cancer. Curr Opin Pharmacol. 2016;29:7-16.

39. Gao ZW, Dong K, Zhang HZ. The roles of CD73 in cancer. Biomed Res Int. 2014;2014:460654

40. Yu YI, et al. Ecto-5'-nucleotidase expression is associated with the progression of renal cell carcinoma. Oncol Lett. 2015;9(6):2485-2494.

41. Zhang B, et al. High expression of CD39/ ENTPD1 in malignant epithelial cells of human rectal adenocarcinoma. Tumour Biol. 2015;36(12):9411-9419.

42. Leclerc BG, et al. CD73 expression is an independent prognostic factor in prostate cancer. Clin Cancer Res. 2016;22(1):158-166.

43. Iannone R, Miele L, Maiolino P, Pinto A, Morello S. Adenosine limits the therapeutic effectiveness of anti-CTLA $4 \mathrm{mAb}$ in a mouse melanoma model. Am J Cancer Res. 2014;4(2):172-181.

44. Allard B, Pommey S, Smyth MJ, Stagg J. Targeting CD73 enhances the antitumor activity of antiPD-1 and anti-CTLA-4 mAbs. Clin Cancer Res. 2013;19(20):5626-5635.

45. Morgan RA, Yang JC, Kitano M, Dudley ME, Laurencot CM, Rosenberg SA. Case report of a serious adverse event following the administration of $\mathrm{T}$ cells transduced with a chimeric antigen receptor recognizing ERBB2. Mol Ther. 2010;18(4):843-851.

46. Ahmed N, et al. Human epidermal growth factor receptor 2 (HER2)-specific chimeric antigen receptor-modified $\mathrm{T}$ cells for the immunotherapy of HER2-positive sarcoma. JClin Oncol. 2015;33(15):1688-1696.

47. Lappas CM, Rieger JM, Linden J. A2A adenosine receptor induction inhibits IFN- $\gamma$ production in murine $\mathrm{CD}^{+} \mathrm{T}$ cells. J Immunol.
2005;174(2):1073-1080.

48. Fredholm BB, Arslan G, Halldner L, Kull B, Schulte $G$, Wasserman W. Structure and function of adenosine receptors and their genes. Naunyn Schmiedebergs Arch Pharmacol. 2000;362(4-5):364-374.

49. Zaretsky JM, et al. Mutations Associated with Acquired Resistance to PD-1 Blockade in Melanoma. N EnglJ Med. 2016;375(9):819-829.

50. Gao J, et al. Loss of IFN- $\gamma$ pathway genes in tumor cells as a mechanism of resistance to antiCTLA-4 therapy. Cell. 2016;167(2):397-404.e9.

51. Shi LZ, et al. Interdependent IL-7 and IFN- $\gamma$ signalling in T-cell controls tumour eradication by combined $\alpha$-CTLA-4+ $\alpha$-PD- 1 therapy. Nat Commun. 2016;7:12335.

52. Wall EA, et al. Suppression of LPS-induced TNF- $\alpha$ production in macrophages by cAMP is mediated by PKA-AKAP95-p105. Sci Signal. 2009;2(75):ra28.

53. Moeller M, et al. Adoptive transfer of geneengineered $\mathrm{CD}^{+}$helper $\mathrm{T}$ cells induces potent primary and secondary tumor rejection. Blood. 2005;106(9):2995-3003.

54. Adusumilli PS, et al. Regional delivery of mesothelin-targeted CAR T cell therapy generates potent and long-lasting CD4-dependent tumor immunity. Sci Transl Med. 2014;6(261):261ra151.

55. Sommermeyer D, et al. Chimeric antigen receptor-modified $\mathrm{T}$ cells derived from defined $\mathrm{CD} 8^{+}$ and $\mathrm{CD} 4^{+}$subsets confer superior antitumor reactivity in vivo. Leukemia. 2016;30(2):492-500.

56. Zarek PE, et al. A2A receptor signaling promotes peripheral tolerance by inducing T-cell anergy and the generation of adaptive regulatory $\mathrm{T}$ cells. Blood. 2008;111(1):251-259.

57. Ohta A, Kini R, Ohta A, Subramanian M, Madasu M, Sitkovsky M. The development and immunosuppressive functions of CD4(+) CD25(+) FoxP3 (+) regulatory $\mathrm{T}$ cells are under influence of the adenosine-A2A adenosine receptor pathway. Front Immunol. 2012;3:190.

58. Naganuma M, Wiznerowicz EB, Lappas CM, Linden J, Worthington MT, Ernst PB. Cutting edge: critical role for A2A adenosine receptors in the T cell-mediated regulation of colitis. J Immunol. 2006;177(5):2765-2769.

59. Chapuis AG, et al. Combined IL-21-primed polyclonal CTL plus CTLA4 blockade controls refractory metastatic melanoma in a patient. J Exp Med. 2016;213(7):1133-1139.

60. Chapuis AG, et al. T-cell therapy using interleukin-21-primed cytotoxic T-cell lymphocytes combined with cytotoxic T-cell lymphocyte antigen-4 blockade results in long-term cell persistence durable tumor regression. JClin Oncol. 2016;34(31): 3787-3795.

61. Johnstone CN, et al. Functional and molecular characterisation of EO771.LMB tumours, a new C57BL/6-mouse-derived model of spontaneously metastatic mammary cancer. Dis Model Mech. 2015;8(3):237-251.

62. Shiloni E, et al. Retroviral transduction of interferon- $\gamma$ cDNA into a nonimmunogenic murine fibrosarcoma: generation of $\mathrm{T}$ cells in draining lymph nodes capable of treating established parental metastatic tumor. Cancer Immunol Immunother. 1993;37(5):286-292.

63. Kershaw MH, et al. Gene-engineered T cells as a superior adjuvant therapy for metastatic cancer. J Immunol. 2004;173(3):2143-2150.

64. Haynes NM, et al. Redirecting mouse CTL against colon carcinoma: superior signaling efficacy of single-chain variable domain chimeras containing TCR- $\zeta$ vs Fc $\varepsilon$ RI $-\gamma$. J Immunol. 2001;166(1):182-187.

65. Darcy PK, et al. Redirected perforin-dependent lysis of colon carcinoma by ex vivo genetically engineered CTL. JImmunol. 2000;164(7):3705-3712.

66. Chang K, Marran K, Valentine A, Hannon GJ. Packaging shRNA retroviruses. Cold Spring Harb Protoc. 2013;2013(8):734-737.

67. Westwood JA, et al. Adoptive transfer of T cells modified with a humanized chimeric receptor gene inhibits growth of Lewis-Y-expressing tumors in mice. Proc Natl Acad Sci US A. 2005;102(52):19051-19056. 